Mr. Archer, of Dublin, under the name Chlamydomyxa. Mr. Archer obtained his specimens crawling upon, and into, the tissues of the bog-moss (Sphagnum) in moor-pools in Westmeath (so far as I recollect). He often found it in a spherical condition, encysted in a cellulose envelope, and more rarely expanding into a most curious network of fine protoplasmic threads, upon which were observed very numerous oblong corpuscles, which slowly travelled along the threads, thus recalling the structure of Labyrinthula described by Cienkowski.

No one has found Archer's Chlamydomyxa, or been in a position to confirm independently his description, up to the present date. He has kindly sent to me encysted specimens of the Chlamydomyxa, but these would not leave their cysts and exhibit the characteristic network and corpuscles; and others whom he has wished to oblige by a sight of this interesting organism have also, I believe, failed to obtain the characteristic phase.

I have from time to time searched for Chlamydomyxa when I have been in a moorland region and had my microscope with me, but have hitherto failed to find it. It was not, therefore, with any great amount of confidence that I gathered some rownish tufts of Sphagnum from a small ditch (with slowlyrunning water) in a clearing in the pine-wood behind the tenniscourt at Pontresina, and brought them to the hotel to search them for Chlamydomyxa. But I found a number of yellowish spheres about $1 / 150$ inch, and less in diameter, which excited my sus picions. After a brief delay these began to throw out protoplasmic filaments, and soon around each was a wonderful series of branching stems of protoplasmic threads, reaching far away from the central yellow granular body and in the most varied directions. Along the threads minute oval corpuscles slowly streamed. There is no doubt that this organism belongs to Archer's genus Chlamydomyxa, and probably enough is specifically distinet from that which he found in Ireland. It is extremely abundant in the Swiss locality.

From what I have seen of Cblamydomyxa, I am now inclined to admit that it is less closely related to Cienkowski's Labyrinthula than I had previously supposed. The moving corpuscles of Cienkowski's organism are very much larger bodies than are the ovoid corpuscles of Chlamydomyxa.

Pontresina, August 23

E. Ray LANKESTER

\section{THE BRITISH ASSOCIATION}

THE fifty-sixth annual meeting of the British Association was opened in Birmingham last night, when Lord Rayleigh resigned the Presidential chair to Sir William Dawson, Principal of McGill College, Montreal. Theattendance at the fourth Birmingham meeting promises to be much above the average, and so far as the Birmingham people are concerned everything has been done to secure success. All the new public buildings, including Mason College and the fine new Art Gallery, have been placed at the disposal of the Sections. The reception-rooms, reading-rooms, writing-rooms, and other general rooms, not omitting the smoking-room, are all that could be desired. All the leading clubs of the town have been thrown open to members; facilities have been given for visiting the various manufactories in the town and neighbourhood; the industrial exhibition in Bingley Hall has been admirably arranged; while there is a formidable programme of social entertainments and excursions. Among the foreign visitors expected, one of the most distinguished is Prof. Haeckel. There is a very large representation, moreover, of colonial science.

The Local Committee have prepared a very excellent Hand-Book of Birmingham for the use of the visitors, the various sections of which are written by specialists. After a General Introduction by Mr. G. J. Johnson, Part I deals with Old Birmingham, by Mr. S. Timmins. The various aspects of Modern Birmingham are treated of by different writers. The section on Art is by four specialists, and the Manufacturing Industries are described by Mr. C. J. Woodward. Part 3 is devoted to Geology and Physiography, and is edited by Prof. C. Lapworth, who has been assisted in the various sections by several local geologists. Part 4, dealing with
Zoology, is edited by Mr. WV. R. Hughes, F.L.S., who also has had the assistance of various local specialists; so with the Botany, edited by Mr. W. Mathews. The appendix comprises a variety of curious and useful information, while a pocket contains a useful sketch-map of the Geology of the Birmingham district, by Prof. Lapworth. lt will thus be seen that the Hand-Brok, while well adapted for its special purpose, is likely to be of permanent value.

Inaugural Address by Sir J. William Dawson, C.M.G., M.A., LL.D., F.R.S., F.G.S., PRINCIPAL AND VICEChancellor of McGill University, Montreal, Canada, President

TWENTY-ONE years have passed away since the last meetin of the British Association in this great central city of Englan.. At the third Birmingham meetiny-that of $1865-\mathrm{I}$ had the pleasure of being present, and had the honour of being one of the Vice-Presidents of Section C. At that meeting my friend John Phillips, one of the founders of the Association, occupied the Presidential chair, and I cannot better introduce what I have to say this evening than by the eloquent words in which he then addressed you :- "As:embled for the third time in this busy centre of industrious England, amid the roar of engines ani clang of hammers, where the strongest powers of nature are trained to work in the fairy chains of art, how softly and rittingly falls upon the ear the accent of Science, the friend of that art, and the guide of that industry! Here where Priestley analysed the air, and Watt obtained the mastery over steam, it well becomes the students of nature to gather round the standard whic' they carried so far into the fie ds of knowledye. And when on other occasions we meet in quiet colleges and academic halls, how gladly welcome is the union of fresh discoveries and new inventions with the solid and venerable truths which are there treasured and taught. Long may such union last; the fair alliance of cultivated thought and practical skill ; for by it labour is dignified and science fertilised, and the condition of human society exalted." These were the words of a man who, while earnest in the pursuit of science, was full of broad and kindly sympathy for his fellow-men, and of hopeful confidence in the future. We have but to turn to the twenty Reports of thiAssociation, issued since 1865 , to see the tealisation of that union of science and art to which he so confidently looked forward, and to appreciate the stupendous results which it has achieved. In one department alone-that to which my predecessor in this chair so eloquently adverted in Aberdeen, the department of education in science-how much has been accomplished since 1865. Phillips himself lived to see a great revolution in this respect at Oxford. But no one in 1865 could have anticipated that immense development of local schools of science of which your own Mason College and your admirable technical, industrial, and art schools are eminent examples. Based on the general education given by the new system of Board-schools, with which the name of the late W. E. Forster will ever be honourably connected, and extending its influence upward to special training and to the highest University examinations, this new scientific culture is opening paths of honourable ambition to the men and women of England scarcely dreamed of in 1865 . I sympathise with the earnest appeal of Sir Lyon Playfair, in his Aberdeen address, in favour of scientific education; but, visiting England at rare intervals, I am naturally more impressed with the progress that has been made than with the vexatious delays which have occurred, and am perhaps better able to appreciate the vast strides that have been taken in the direction of that complete and all-pervading culture in science which he has $\leqslant 0$ ably advocated.

No one could have anticipated twenty years ago that a Birmingham manufacturer, in whose youthful days there were no schools of science for the people, was about to endow a College, not only worthy of this great city, but one of its brightest ornaments. ${ }^{1}$ Nor could any one have foreseen the great development of local scientific Societies, like your Midland Institute and Philosophical Society, which are now flourishing in every large town and in many of those of less magnitude. The period of twenty-one years that has elapsed since the last Birmingham meeting has also been an era of public museums and laboratories for the teaching of science, from the magnificent national

It was in 1865 that Sir Josiah Mason was, quietly and without any public note, beginning to lay the foundation of his orrhanage at Erdington. 
institutions at South Kensington and those of the great Universities and th-ir Colleges down to those of the schools and fieldclubs in country towns. It has besides been an era of gigantic progress in original work and in publication-a progress so rapid that workers in every branch of study have been reluctantly obliged to narrow in more and more their range of reading and of effort to keep abreast of the advance in their several departments. Lastly, these twenty-one years have been characterised as the "coming of age" of that great system of philosophy with which the names of three Englishmen-Darwin, Spencer, and Wallace-are associated as its founders. Whatever opinions one may entertain as to the sufficiency and finality of this philosophy, there can be no question as to its influence on scientific thought. On the one hand, it is inaccurate to compare it with so entirely different thing - as the discovery of the chemical elements and of the law of gravitation; on the other, it is scarcely fair to characterise it as a mere " confused development" of the mind of the age. It is indeed a new attempt of science in its maturer years to grapple with those mysterious questions of origins which occupied it in the days of its infancy, and it is to be hoped that it may not, like the Titans of ancient fable, be hurled back from heave:i, or, like the first mother, find the knowledge to $\mathrm{which}$ it aspires a bitter thing. In any case we should fully understand the responsibility which we incur when in these times of full-grown science we venture to deal with the great problem of origins, and should be prepared to find that in this field the new philosophy, like those which have preceded it, may meet with very imperfect success. The agitation of these subjects has already brought science into close relations, sometimes friendly, so rietimes hostile, it is to re hoped in the end helpful, with those great and awful questions of the ultimate de stiny of humanity, and its relations to its Creator, which must always be nearer to the human heart than any of the achievements of science on its own ground. In entering on such questions we should proceed with caution and reverence, feeling that we are on holy ground, and that though, like Moses of old, we may be armed with all the learning of our time, we are in the presence of that which while it burns is not consumed; of a mysiery which neither observation, experiment, nor induction can ever fully st lve.

In a recent addre s, the late President of the Royal Society called attention to the fact the $t$, within the life-time of the older men of science of the present day, the greater part of the vast body of knowledge included in the modern sciences of physics, chemistry, biology, and geology has been accumulated, and the most important advances made in its application to such common and familiar things as the railway, ocean navigation, the electric telegraph, electric lighting, the telephone, the germtheory of disease, the use of anæsthetics, the processes of metallurgy, and the dyeing of fabrics. Even since the last meeting in this city much of this great work has been done, and has led to general results of the most marvellous kind. What at that time could have appeared more chimerical than the opening up, by the enterprise of one British colony, of a shorter road to the East by way of the extreme West, realising what was happily called by Milton and Cheadle "the new North-West Passage," making Japan the next neighbour of Canada on the west, and offering to Britain a new way to her Eastern possessions; or than the possibility of this Association holding a successful meeting on the other side of the Atlantic? We have now an invitation to meet in Australia, and may, if we please, proceed thither by the Canadian Pacific Railway and its new lines of steamers, returning by the Suez Canal. ${ }^{1}$ 'To-day this is quite as feasible as the Canadian visit would have been in 1865. It is science that has thus brought the once widely separated parts of the world nearer to each other, and is breaking down those geographical barriers which have separated the different portions of our widely extended British race. Its work in this is not yet complete. Its goal to-day is its starting-point to-morrow. It is as far as at any previous time from seeing the limit of its conquests, and every victory gained is but the opening of the way for a further advance.

By its visit to Canada the British Association has asserted its Imperial character, and has consolidated the scientific interests of Her Majesty's dominions, in advance of that great gathering of the industrial products of all parts of the Empire now on exhibition in London, and in advance of any political plans of

: It is expected that, on the completion of the whole of the connections of the Canadian Pacific Railway, the time from ocean to ocean may be rediced to 116 hours, and from London to Hong Kong to 27 days.
Imperial federation. ${ }^{1}$ There has even been a project before us for an International Scientific Convention, in which the great English Republic of America shall take part-a project the realisation of which was to some extent anticipated in the fusion of the members of the British and American Associations at Montreal and Philadelphia in 1884 . As a Canadian, as a past President of the American Association, and now honoured with the Presidency of this Association, I may be held to represent in my own person this scientific union of the British Islands, of the various Colonies, and of the great Republic, which, whatever the difficulties attending its formal accomplishment at present, is certain to lead to an actual and real union for scientific work. In furtherance of this I am glad to see here to-day influential representatives of most of the British Colonies, of India, and of the United States. We welcome here also delegates from other countries, and though the barrier of language may at present prevent a larger union, we may entertain the hope that Britain, America, India, and the Colonies, working together in the interest of science, may ultimately render our English tongue the most general vehicle of scientific thought and discovery - a consummation of which I think there are, at present, many indications.

But, while science marches on from victory to victory, its path is marked by the resting-places of those who have fought its battles and assured its advance. In looking back to 1865 there rise before me the once familiar countenances of Phillips, Murchison, Lyell, Forbes, Jeffreys, Jukes, Rolleston, Miller, Spottiswoode, Fairbairn, Gassiot, Carpenter, and a host of others, present in full vigou: at that meeting, but no more with us. These were veterans of science; but, alas! many then young and rising in fame are also numbered with the dead. It may be that before another Birmingham meeting many of us, the older members now, will also have passed away. But these men have left behind them ineffaceable monuments of their work, in which they still survive, and we rejoice to believe that, though dead to us, they live in that company of the great and good of all ages who have entered into that unseen Universe where all that is high and holy and beautiful must go on accumulating till the time of the restitution of all things. Let us follow their example and carry on their work, as God may give us power and opportunity, gathering in precious stores of knowledge and of thought, in the belief that all truth is immortal, and must go on for ever bestowing blessings on mankind. Thus will the memory of the mighty dead remain to us as a power which,

\section{Beaco ns from the abode where the eternal are."}

I do not wish, however, to occupy your time longer with general or personal matters, but rather to take the opportunity afforded by this address to invite your attention to some topics of scientific interest. In attempting to do this, I must have before me the warning conveyed by Prof. Huxley, in the address to which I have already referred, that in our time science, like Tarpeia, may be crushed with the weight of the rewards bestowed on her. In other words, it is impossible for any man to keep pace with the progress of more than one limited branch of science, and it is equally impossible to find an audience of scientific men of whom anything more than a mere fraction can be expected to take an interest in any one subject. There is, however, some consolation in the knowledge that a speaker who is sufficiently simple for those who are advanced specialists in other departments, will of necessity be also sufficiently simple to be understood by the general public who are specialists in nothing. On this principle a geologist of the old school, accustomed to a great variety of work, may hope so to scatter his fire as to reach the greater part of the audience. In endeavouring to secure this end, I have sought inspiration from that ocean which connects rather than separates Britain and America, and may almost be said to be an English sea-the North Atlantic. The geological history of this depression of the earth's crust, and its relation to the continental masses which limit it, may furnish a theme at once generally intelligible and connected with great questions as to the structure and history of the earth, which have excited the attention alike of physicists, geologists, biologists, geographers, and ethnologists. Should I, in treating of these questions, appear to be somewhat abrupt and dogmatic, and to indicate rather than state the

${ }^{x}$ I should note here, in connection with this, the valuable volume of "Canadian Economics," edited by Mr. D. A. P. Watt, which was one of the results of the Montreal meeting. 
evidence of the general views announced, I trust you will kindly attribute this to the exigencies of a short address.

If we imagine an observer contemplating the earth from a convenient distance in space, and scrutinising its features as it rolls before him, we may suppose him to be struck with the fact that eleven-sixteenths of its surface are covered with water, and that the land is so unequally distributed that from one point of view he would see a hemisphere almost exclusively oceanic, while nearly the whole of the dry land is gathered in the opposte hemisphere. He might observe that the great oceanic area of the Pacific and Antarctic Oceans is dotted with islands-like a shallow pool with stones rising above its surface-as if its general depth were small in comparison with its area. He might also notice that a mass or belt of land surrounds each Pole, and that the ncrthern ring sends off to the southward three vast tongues of land and of mountain-chains, terminating respectively in South America, South Africa, and Australia, towards which feebler and insular processes are given off by the Antarctic continental mass. This, as some geographers have observed, ${ }^{1}$ gives a rudely three-ribbed aspect to the earth, though two of the three ribs are crowded together and form the Europ-asian mass, or double continent, while the third is isolated in the single continent of America. He might also observe that the northern girdle is cut across, so that the Atlantic opens by a wide space into the Arctic Sea, while the Pacific is contracted towards the north, but confluent with the Antarctic Ocean. The Atlantic is also relatively deeper and less cumbered with islands than the Pacific, which has the higher ridges near its shores, constituting what some visitors to the Pacific coast of America have not inaptly called the "back of the world," while the wider slopes face the narrower ocean, into which for this reason the greater part of the drainage of the land is poured. ${ }^{2}$ The Pacific and Atlantic, though both depressions or flattenings of the earth, are, as we shall find, different in age, character, and conditions; and the Atlantic, though the smaller, is the older, and, from the geological point of view, in some respects the more important of the two.

If our imaginary observer had the means of knowing anything of the rock-formations of the continents, he would notice that those bounding the North Atlantic are in general of great age, some belonging to the Laurentian system. On the other hand, he would see that many of the mountain-ranges along the Pacific are comparatively new, and that modern igneous action occurs in connection with them. Thus he might be led to believe that the Atlantic, though comparatively narrow, is an older feature of the earth's surface, while the Pacific belongs to more modern times. But he would note in connection with this that the oldest rocks of the great continental masses are mostly toward their northern ends, and that the borders of the northern ring of land and certain ridges extending southwards from it constitute the most ancient and permanent elevations of the earth's crust, though now greatly surpassed by mountains of more recent age nearer the equator. Before leaving this general survey we may make one further remark. An observer looking at the earth from without would notice that the margins of 'the Atlantic and the main lines of direction of its mountain-chains are north-east and south-west, and north-west and south-east, as if some early causes had determined the occurrence of elevations along great circles of the earth's surface tangent to the polar circles.

We are invited by the preceding general glance at the surface of the earth to ask certain questions respecting the Atlantic :(1) What has at first determined its position and form? (2) What changes has it experienced in the lapse of geological time? (3) What relations have these changes borne to the development of life on the land and in the water? (4) What is its probable future?

Before attempting to answer these questions, which I shall not take up formally in succession, but rather in connection with each other, it is necessary to state as briefly as possible certain general conclusions respecting the interior of the earth. It is popularly supposed that we know nothing of this beyond a superficial crust perhaps averaging 50,000 to 100,000 feet in thickness. It is true we have no means of exploration in the earth's interior, but the conjoined labours of physicists and geologists have now proceeded sufficiently far to throw much inferential light on the subject, and to enable us to make some general affirmations with

×Dana, "Manual of Geology," introductory part. Green, "Vestiges of a Molten Globe," has summed up these facts.

" Mr. Mellard Reade, in two Presidential addresses before the Geological Society of Liverpool, has well illustrated this point and its geological consequence. certainty; and these it is the more necessary to state distinctly, since they are often treated as mere subjects of speculation and fruitless discussion.

(I) Since the dawn of geological science it has been evident that the crust on which we live must be supported on a plastic or partially liquid mass of heated rock, approximately uniform in quality under the whole of its area. This is a legitimate conclusion from the wide distribution of volcanic phenomena, and from the fact that the ejections of volcanoes, while locally of various kinds, are similar in every part of the world. It led to the old idea of a fluid interior of the earth, but this is now generally abandoned, and this interior heated and plastic layer is regarded as merely an under-crust.

(2) We have reason to believe, as the result of astronomical investigations, ${ }^{1}$ that, notwithstanding the plasticity or liquidity of the under-crust, the mass of the earth-its nucleus as we may call it-is practically solid and of great density and hardness. Thus we have the apparent paradox of a solid yet fluid earth, solid in its astronomical relations, liquid or plastic for the purposes of volcanic action and superficial movements. ${ }^{2}$

(3) The plastic sub-crust is not in a state of dry igneous fusion, but in that condition of aqueo-igneous or bydro-thermic fusion which arises from the action of heat on moist substances, and which may either be regarded as a fusion or as a species of solution at a very high temperature. This we leain from the phenomena of volcanic action, and from the composition of the volcanic and plutonic rocks, as well as from such chemical experiments as those of Daubrée and of Tilden and Shenstone. ${ }^{3}$

(4) The interior sub-crust is not perfectly homogeneous, I ut may be roughly divided into two layers or magmas, as they have been called : an upper, bighly siliceous or acidic, of low specific gravity and light-coloured, and corresponding to such kinds of plutonic and volcanic rocks as granite and trachyte ; and a lower, less siliceous or more basic, more dense, and more highly charged with iron, and corresponding to such igneous rocks as the dolerites, basalts, and kindred lavas. It is interesting here to note that this conclusion, elaborated by Durocher and Von Waltershausen, and usually connected with their names, appears to have been first announced by John Phillips, in his "Geologi-cal Manual," and as a mere common-sense deduction from the observed phenomena of volcanic action and the probable results of the gradual cooling of the earth. It receives striking confirmation from the observed succession of acidic and basic volcanic rocks of all geological periods and in all localities. It would even seem, from recent spectroscopic investigations of 1 ockyer, that there is evidence of a similar succession of magmas in the heavenly bodies, and the discovery by Nordenskjö!d of native iron in Greenland basalts affords a probability that the inner magma is in part metallic. ${ }^{5}$

(5) Where rents or fissures form in the upper crust, the material of the lower crust is forced upward by the pressure of the less supported portions of the former, giving rise to volcanic phenomena either of an explosive or quiet character, as may be determined by contact with water. The underlying material

× Hopkins, Mallet, Sir William Thomecn, and Prof. G. H. Darwin main tain the solidity and rigidity of the earth on astronomical grounds; but different conclusions have been reached by Hennesey, Delaunay, and Airy. In America, Barnard and Crosby, Dutton, Le Conte, and Wadsworth have discussed these questions.

2 An objection has teen taken to the effect that the supposed ellipsoidal An objection has keen taken to the effect that the supposed ellipsoidal form of the equator is inconsistent with a plastic sub-crust. But this ellips oidal form is not absolutely certain, or, if it exists, is very minute. Bonney may be slowly mobile under long-continued pressure, while yet rigid with may be slowly mobile under long-cont

3 Phil. Trans., 1884 . Also Crosby in Proc. Boston Soc. Nat. Hist., 1883

4 Phillips says (" Manual of Geology," 1855, p. 493):-“If we regard them (the internal crystalline rocks) as acquiring solidification by cooling in zones parallel to the surface, we should have sheets of granitic and basaltic rocks generated below, the first uppermost, the last undermost, while above the several strata were produced in a series beginning at the bottom. In this sense the rocks of fusion may be called, with Lyell, hypogene. Certainly under par$t$ cular areas of country are found evidence of the liquefaction of one set of igneous products after the solidification of others. Many dykes of basalt traversing granite show themselves to have been in fusion after the solidification of the granite." In various forms Phillips returns to this idea, as at pr. 556 and 564 , in that unpretending manner which was his wont. Dr. Sterry $\mathbf{H u n}$ has kindly directed my attention to the fact of Phillips's right of priority in this matter. Durocher in 1857 elaborated the theory of magmas in the Annales des Mines, and we are indebted to Dutton, of the United States Geological Survey, for its detailed application to the remarkable volcanic outflows of Western America.

5 These basalts occur at Ovifak, Greenland. Andrews has found small particles of iron in British basalts. Prestwich and Judd bave referred to the bearing on general geology of these facts, and of Lockyer's suggesticns. 
may also be carried to the surface by the agency of heated water, producing those quiet discharges which Hunt has named crenitic. It is to be observed here that explosive volcanic phenomena, and the formation of cones, are, as Prestwich has well remarked, characteristic of an old and thickened crust; quiet ejection from fissures and hydro-thermal action may have been more common in earlier periods and with a thinner over-crust.

(6) The contraction of the earth's interior by cooling and by the emission of material from below the over-crust, has caused this crust to press downward, and therefore laterally, and so to effect great bends, folds, and plications; and these modified subsequently by surface denudation constitute mountain-chains and continental plateaus. As Hall long ago pointed out, ${ }^{1}$ such lines of folding have been produced more especially where thick sediments had been laid down on the sea-bottom. Thus we have here another apparent paradox, namely, that the elevations of the earth's crust occur in the places where the greatest burden of detritus has been laid down upon it, and where consequently the crust has been softened and depressed. We must beware, in this connection, of exaggerated notions of the extent of contraction and of crumbling required to form mountains. Bonney has well shown, in lectures delivered at the London Institution, that an amount of contraction, almost inappreciable in comparison with the diameter of the earth, would be sufficient; and that as the greatest mountain-chains are less than I/600 of the earth's radius in height, they would on an artificial globe a foot in diameter be no more important than the slight inequalities that might result from the paper gores overlapping each other at the edges.

(7) The crushing and sliding of the over-crust inplied in these movements raise some serious questions of a physical character. One of these relates to the rapidity or slowness of such movements, and the consequent degree of intensity of the heat developed, as a possible cause of metamorphism of rocks. A nother has reference to the possibility of changes in the equilibrium of the earth itself as resulting from local collapse and ridging. These questions in connection with the present dissociation of the axis of rotation from the magnetic poles, and with changes of climate, have attracted some attention, ${ }^{2}$ and probably deserve further consideration on the part of physicists. In so. far as geological evidence is concerned, it would seem that the general association of crumbling with metamorphism indicates a certain rapidity in the process of mountain-making, and consequent development of heat, and the arrangement of the older rocks around the Arctic basin forbids us from assuming any extensive movement of the axis of rotation, though it does not exclude changes to a limited extent. I hope that Prof. Darwin will discuss these points in his address to the Physical Section.

I wish to formulate these principles as distinctly as possible, and as the result of all the long series of observations, calculations, and discussions since the time of Wemer and Hutton, and in which a vast number of able physicists and naturalists have borne a part, because they may be considered as certain deductions from our actual knowledge, and because they lie at the foundation of a rational physical geology.

We may popularise these deductions by comparing the earth to a drupe or stone-fruit, such as a plum or peach, somewhat dried up. It has a large and intensely hard stone and kernel, a thin pulp made up of two layers, an inner more dense and darkcoloured, and an outer less dense and lighter-coloured. These constitute the under-crust. On the outside it has a thin membrane or over-crust. In the process of drying it has slightly shrunk, so as to produce ridges and hollows of the outer crust, and this outer crust has cracked in some places, allowing portions of the pulp to ooze out-in some of these its lower dark substance, in others its upper and lighter material. The analogy extends no further, for there is nothing in our withered fruit to represent the oceans occupying the lower parts of the surface or the deposits which they have laid down.

Keeping in view these general conclusions, let us now turn to their bearing on the origin and history of the North Atlantic.

Though the Atlantic is a deep ocean, its basin does not constitute so much a depression of the crust of the earth as a flattening of it, and this, as recent soundings have shown, with a slight ridge or elevation along its middle, and banks or terraces

I Hall (American Association Address, 1857, subsequently republished, with additions, as "Contributions to the Geological History of the American Continent," Mallet), Rogers, Dana, Le Conte, \&c.

' See recent papers of Oldham and Fisher in the Geological Magazine and Philosophical Magazine, July 1886. Also Péroche, "Revol. Polaires" (Paris, 1886). fringing the edges, so that its form is not so much that of a basin as that of a shallow plate with its middle a little raised. Its true permanent margins are composed of portions of the over-crust folded, ridged up, and crushed, as if by lateral pressure emanating from the sea itself. We cannot, for example, look at a geological map of America without perceiving that the Appalachian ridges, which intervene between the Atlantic and the St. Lawrence Valley, have been driven bodily back by a force acting from the east, and that they have resisted this pressure only where, as in the Gulf of St. Lawrence and the Catskill region of New York, they have been protected by outlying masses of very old rocks, as, for example, by that of the Island of Newfoundland and that of the Adirondack Mountains. The admirable work begun by my friend and fellow-student, Prof. James Nicol, followed up by Hicks, Lapworth, and others, and now, after long controversy, fully confirmed by the recent observations of the Geological Survey of Scotland, has shown the most intense action of the same kind on the east side of the ocean in the Scottish highlands; and the more widely distributed Eozoic rocks of Scandinavia may be appealed to in further evidence of this. ${ }^{1}$

If we now inquire as to the cause of the Atlantic depression, we must go back to a time when the areas occupied by the Atlantic and its bounding coasts were parts of a shoreless sea in which the earliest gneisses or stratified granites of the Laurentian age were being laid down in vastly extended beds. These ancient crystalline rocks have been the subject of much discussion and controversy, and as they constitute the lowest and probably the firmest part of the Atlantic sea-bed, it is necessary to inquire as to their origin and history. Dr. Bonney, the late President of the Geological Society, in his anniversary address, and Dr. Sterry Hunt, in an elaborate paper communicated to the Royal Society of Canada, have ably summerl up the hypotheses as to the origin of the oldest Laurentian beds. At the basis of these hypotheses lies the admission that the immensely thick beds of orthoclase gneiss, which are the oldest stratified rocks known to us, are substantially the same in composition with the upper or siliceous magma or layer of the under-crust. They are, in short, its materials either in their primitive condition or merely re-arranged. One theory considers them as original products of cooling, owing their lamination merely to the successive stages of the process. Another view refers them to the waste and re-arrangement of the materials of a previously massive granite. Still another holds that all our granites really arise from the fusion of old gneisses of originally aqueous origin ; while a fourth refers the gneisses themselves to molecular changes effected in granite by pressure. These several views, in so far as they relate to the oldest or fundamental Laurentian gneiss, may be arranged under the following heads :-(x) Endo. plutonic, or that which regards all the old gneisses as molten rocks cooled from without inward in successive layers. ${ }^{2}$ (2) Exoplutonic, or that which considers them as made up of matter ejected from below the upper crust in the manner of volcanic action. ${ }^{3}$ (3) Metamorphic, which supposes the old gneisses to arise from the crystallisation of detrital matter spread over the sea-bottom, and either igneous or derived from the decay of igneous rocks. ${ }^{4}$ (4) Chaotic or Thermo-chaotic, or the theory of deposit from the turbid waters of a primæval ocean either with or without the aid of heat. ${ }^{5}$ In one form this was the old theory of Werner. (5) Crenitic or Hydro-thermic, which supposes the action of heated waters penetrating below the crust to be con. stantly bringing up to the surface mineral matters in solution and depositing these so as to form feldspathic and other rocks. ${ }^{6}$ r Address to the Geological Section, by Prof. Judd, Aberdeen meeting,
1885. According to Rogers, the crumpling of the Appalachians has reduced a breadth of 158 miles to about 60 .

2 Naumann, Phillips, Durocher, McFarlane, \&c.

3 Clarence King, Tornebohm, Marr, \&c.

4 Lyell, Kopp. Reusch, Judd, \&c. 5 Scrope, Delabeche, Daubrée. 6 Hunt, loc. cit. The following is Dr. Hunt's summary statement of this theory :-" The globe consolidating at the centre left, it is cunceived, a super. ficial layer of basic silicates, which has yielded all the fixed elements of the earth's crust. This layer formed the first land and the floor of the primæval sea, the acid waters of which, permeating and partially decomposing it, became thereby chemically neutralised. This last-cooled layer, mechanically disintegrated, saturated with water, and heated by the central mass, was the disintegrated, saturated with water, and heated by the central mass, was the source of mineral springs, holding in solution the silicates which built up the ancient gneisses and similar rocks. Granitic veins and zeolites are due to survivals of the process which generated the gneissic rocks. The hypothesi of their formation from materials brought to the surface by mineral spring from the primitive basic layer affords, it is claimed, the elements of a complete and intelligible explanation of the origin of the Eozoic rocks. This upward lixiviation of the primitive mass, and the deposition over it of an division of the mass thus established would correspond to that of the trachytic 
It will be observed, in regard to these theories, that none of them supposes that the old gneiss is an ordinary sediment, but that all regard it as formed in exceptional circumstance;, these circumstances being the absence of land and of sub-aërial decay of rock, and the presence wholly or principally of the material of the upper surface of the recently harclened crust. This being granted, the question arises, Ought we not to combine these several theories and to believe that the cooling crust has hardened in successive layers from without inward; that at the same time fissures were locally discharging igneous matter to the surface; that matter held in suspension in the ocean, and matter held in solution by heated waters rising from beneath the outer crust were mingling their materials in the deposits of the primitive ocean? It would seem that the combination of all these agencies may safely be invoked as causes of the pre-Atlantic deposits. This is the eclectic position which I endeavoured to maintain in my address before the Minneapolis meeting of the American Association in 1883 , and which I still bold to be in every way probable.

A word here as to metamorphism, a theory which, like many others, has been first run to death and then discredited, but which to the moderate degree in which it was originally held by Lyell is still valid. Nothing can be more certain than that the composition of the Laurentian gneisses forbids us to suppose that they can be ordinary sediments metamorphosed. They are rocks peculiar in their origin, and not paralleled unless exceptionally in later times. On the other hand, they have undoubtedly experienced very important changes, more especially as to crystallisation, the state of combination of their ingredients, and the development of disseminated minerals $;{ }^{1}$ and while this may in part be attributed to the mechanical pressure to which they have been subjected, it requires also the action of hydrothermic agencies. Any theory which fails to invoke both of these kinds of force must necessarily be partial and imperfect.

But all metamorphic rocks are not of the same character with the gneisses of the Lower Laurentian. Even in the Middle and Upper Laurentian we have metamorphic rocks, e.g. quartzite and limestone, which must originally have been ordinary aqueous deposits. Still more in the succeeding Huronian and its associated series of beds, and in the Lower Palæozoic, local metamorphic change has been undergone by rocks quite similar to those which in their unaltered state constitute regular sedimentary deposits. In the case of these later rocks it is to be borne in mind that, while some may have been of volcanic origin, others may have been sediments rich in undecomposed fragments of silicates. It is a mistake to suppose that the ordinary decay of stratified siliceous rocks is a process of kaolinisation so perfect as to eliminate all alkaline matters. On the contrary, the fact, which Judd has recently well illustrated in the case of the mud of the Nile, applies to a great number of similar deposits in all parts of the world, and shows that the finest sediments have not usually been so completely lixiviated as to be destitute of the basic matters necessary for their conversion into gneiss, micaschist, and similar rocks when the necessary agencies of metamorphism are applied to them, and this quite independently of any extraneous matters introduced into them by water or otherwise. Still it must be steadily kept in view that many of the old pre-Cambrian crystalline rocks must have been different originally from those succeeding them, and that consequently these last even when metamorphosed present different characters.

I may remark here that, though a palæontologist rather than a lithologist, it gives me great pleasure to find so much attention now given in this country to the old crystalline rocks, and to their study microscopically and chemically as well as in the field, a work in which Sorby and Allport were pioneers. As a pupil of the late Prof. Jameson, of Edinburgh, my own attention was early attracted to the study of minerals and rocks as the stable foundations of geological science; and as far back as I84I I had learnt of the late Mr. Sanderson, of Edinburgh, who worked at Nicol's sections, how to slice rocks and fossils; and since that time I have been in the habit of examining everything

and doleritic magmas, which have been conjectured to be the sources of two great types of eruptive rocks. Inasmuch, however, as according to the present hypothesis these two layers of basic and acidic matters are the results of aqueous action, and not of an original separation in a plutonic mass, as imagined by Phillips and Durocher, their composition would be subiect to many local variations."

I The first of these is what Bonney has called Metasiasis. The second and third come under the name Metacrasis. Methylosis, or change of substance, is altogether exceptional, and not to be crcdited except on the best evidence, or in cases where yolatile matters have been expelled, as in the change of hrematite into magnetite, or of bituminous coalinto anthracite. with the microscope. The modern developments in this direction are therefore very gratifying, even though, as is natural, they may sometimes appear to be pushed to r far or their value over-estimated.

That these old gneisses were deposited not only in what is now the bed of the Atlantic, but also on the great continental areas of America and Europe, any one who considers the wide extent of these rocks represented on the map recently published by Prof. Hull can readily understand (Trans. Royal Irish Academy). It is true that Hull supposes that the basin of the Atlantic itself may have been land at this time, but there is no evidence of this, more especially as the material of the gneiss could not have been detritus derived from sub-aërial decay of rock.

Let us suppose, then, the floor of old Ocean covered with a flat pavement of gneiss, or of that matcrial which is now gneiss, the next question is, How and when did this original bed become converted into sea and land? Here we have some things certain, others most debatable. That the cooling mass, especially if it was sending out volumes of softened rocky material, either in the exoplutonic or in the crenitic way, and piling this on the surface, must soon become too small for its shell, is apparent but when and where would the collapse, crushing, and wrinkling inevitable from this cause begin? Where they did begin is indicated by the lines of mountain-chains which traverse the Laurentian districts; but the reason why is less apparent. The more or less unequal cooling, hardening, and conductive power of the outer crust we may readily assume. The driftage un. equally of water-borne detritus to the south-west by the bottom currents of the sea is another cause, and, as we shall soon see, most effective. Still another is the greater cooling and hardening of the crust in the polar regions, and the tendency to collapse of the equatorial protuberance from the slackening of the earth's rotation. Besides these the internal tides of the earth's substance at the times of solstice would exert an oblique pulling force on the crust, which might tend to crack it along diagonal lines. From whichever of these causes or the combination of the whole, we know that within the Laurentian time folded portions of the earth's crust hegan to rise above the general surface in broad belts running from north-east to south-west, and from north-west to south-east, where the older mouritains of Eastern America and Western Europe now stand, and that the subsidence of the oceanic areas allowed by this crumpling of the crust permitted other areas on both sides of what is now the Atlantic to form limited table-lands. ${ }^{1}$ This was the beginning of a process repeated again and again in subsequent times, and which began in the Middle Laurentian, when for the first time we find beds of quartzite, limestone, and iron ore, and graphitic beds, indicating that there was already land and water, and that the sea, and perhaps the land, swarmed with animal and plant life of forms unknown to us for the most part now. Independently of the questions as to the animal nature of Eozoon, I hold that we know, as certainly as we can know anything inferentially, of the existence of these primitive forms of life. If I were to conjecture what were the early forms of plant and animal life, I would suppose that just as in the Palæozoic the acrogens culminated in gigantic and complex forest trees, so in the Laurentian the Algæ, the lichens, and the mosses grew to dimensions and assumed complexity of structure unexampled in later times, and that in the sea the humbler forms of Protozoa and Hydrozoa were the dominant types, but in gigantic and complex forms. The land of this period was probably limited, for the most part, to high latitudes, and its aspect, though rore rugged and abrupt, and of greater elevation, must have been of that character which we still see in the Laurentian hills. The distribution of this ancient land is indicated by the long lines of old Laurentian rock extending from the Labrador coast and the north shore of the St. Lawrence, and along the eastern slopes of the Appalachians in America, and the like rocks of the Hebrides, the Western Highlands, and the Scandinavian mountains. A small but interesting remnant is that in the Malvern Hills, so well described by Holl. It will be well to note here, and to fix on our minds, that these ancient ridges of Eastern America and Western Europe have been greatly denuded and wasted since Laurentian tin.es, and that it is along their eastern sides that the greatest sedimentary accumulations have been deposited.

From this time dates the introduction of that dominance of

I Daubrée's curious experiments on the contraction of caoutchouc balloons partially hardened by coating with varnish, shows how small inequalitie- of and also that transverse as well as longittidinal wainklirig might occur. 
existing causes which forms the ba is of uniformitarianism in geology, and which had to go on with various and great modifications of detail, through the successive stages of the geological history, till the land and water of the northern hemisphere attained to their present complex structure.

So soon as we have a circumpolar belt or patches of Eozoic (or Archæan, or pre-Cambrian, if these terms are preferred) land, and ridges running southward from it, we enter on new and $m$ re complicated methods of growth of the continents and seas. Here we are indebted to Le Conte for clearly pointing out that our original Eozoic tracts of continent were in the earliest times areas of deposition, and that the first elevations of land out of the primæval ocean must have differed in important points from all that have succeeded them; but they were equally amenable to the ordinary laws of denudation. Portions of these oldest crystalline rocks, raised out of the protecting water, were now eroded by atmospheric agents, and especially by the carbonic acid, then existing in the atmosphere perhaps more abundantly than at present, under whose influence the hardest of the gneissic rocks gradually decay. The Arctic lands were subjected in arldition to the powerful mechanical force of frost and thaw. Thus every shower of rain and every swollen stream would carry $i$ to the sea the products of the waste of land, sorting them into fine clays and coarser sands; and the cold currents which cling to the ocean bottom, now determined in their courses, not merely by the earth's rotation, but also by the lines of folding on both sides of the Atlantic, would carry south-westward, and pile up in marginal banks of great thickness, the debris produced from the rapid waste of the land already existing in the Arctic regions. The Atlantic, opening widely to the north, and having large rivers pouring into it, was especially the ocean characterised, as time advanced, by the prevalence of these phenomena. Thus throughout the geological history it has happened that, while the middle of the Atlantic has received merely organic deposits of shells of Foraminifera and similar organisms, and this probably only to a small amount, its margins have had piled upon them beds of detritus of immense thickness. Prof. Hall, of Albany, w is the first geologist who pointed out the vast cosmic importance of these deposits, and that the mountains of both sides of the Atlantic owe their origin to these great lines of deposition, a'ong with the fact, afterwards more fully insisted on by Rogers, that the portions of the crust which received these masses of debris became thereby weighted down and softened, and were more liable than other parts to lateral crushing. ${ }^{1}$

Thus in the later Eozoic and early Palæozoic times, which succeeded the first foldings of the oldest Laurentian, great ridges were thrown up, along the edges of which were beds of limestone, and on their summits and sides thick masses of ejected jgneous rocks. In the bed of the central Atlantic there are no such accumulations. It must have been a flat, or slightly ridged, plate of the ancient gneiss, hard and resisting, though perhaps with a few cracks, through which igneous matter welled up, as in Iceland and the Azores in more modern times. In this condition of things we have causes tending to perpetuate and extend the distinctions of ocean and continent, mountain and plain, already begun; and of these we may more especially note the continued subsidence of the areas of greatest marine deposition. This has long attracted attention, and affords very convincing evidence of the connestion of sedimentary deposit as a cause with the subsidence of the crust. ${ }^{2}$

We are indebted to a French physicist, M. Faye (Revue Scientifique, I886), for an important suggestion on this subject. It is that the sediment accumulated along the shores of the ocean pre-

I The connection of accumulation with subsidence was always a familiar consideration with geologists; but Hall seems to have been the first to state its true significance as a geological factor, and to see that those portions of the crust which are weighted down by great detrital accumulations are necessarily those which, in succeeding movements, were elevated into mountains. Other American geologists, as Dana, Rogers, Hunt. Le Conte, Crosby, \&c., have followed up Hall's primary suggestion, and in England, Hicks, Fisher, Starkie Gardner, Hull, and others, have brought it under Hotice, and it Starkie Gardner, Hull, and others, have brought it under
enters into the great generalisations of Lyell on these subjects.

2 Dutton in "Report of U.S. Geological Survey," $188 \mathbf{r}$. From facts stated
(n) in this report and in my "Acadian Gevlogy," it is apparent that in the in this report and in my "Acadian Genlogy," it is apparent that in the
Western States and in the coal-field of Nova Scotia shallow-water deposits have been laid down up to thicknesses of 10,000 to 20,000 feet in connection have been laid down up to thicknesses of 10,000 to 20,000 feet in connection
with continuous subsidence. See also a paper by Ricketts in the Geol. Mas. with continuous subsidence. See also a paper by Ricketts in the Geol. Mag.
$\mathbf{1 8 8}_{3}$. It may be well to add here that this doctrine of the subsidence of wide 188. It may be well to add here that this doctrine of the subsidence of wide
areas being caused by deposition cloes not justify the conclusion of certain glacialists that snow and ice have exercised a like power in glacial periods. In truth, as will appear in the sequel, great accumulations of snow and ice require to be preceded by subsidence, and wide continental areas can never be covered with deep snow, while of course ice can cause no addition of weight to submerged areas. sented an obstacle to radiation, and consequently to cooling of the crust, while the ocean floor, unprotected and unweighted, and constantly bathed with currents of cold water, having great power of convection of heat, would be more rapidly cooled, and so would become thicker and stronger. This suggestion is complementary to the theory of Prof. Hall, that the areas of greatest deposit on the margins of the ocean are necessarily those of greatest folding and consequent elevation. We have thus a hard thick resisting ocean bottom which, as it settles down toward the interior, under the influence of gravity, squeezes upward and folds and plicates all the soft sediments deposited on its edges. The Atlantic area is almost an unbroken cake of this kind. The Pacific area has cracked in many places, allowing the interior fluid matter to ooze out in volcanic ejections.

It may be said that all this supposes a permanent continuance of the ocean basins, whereas many geologists postulate a midAtlantic continent ${ }^{1}$ to give the thick masses of detritus found in the older formations both in Eastern America and Western Europe, and which thin off in proceeding into the interior of both continents. I prefer with IIall to consicler these belts of sediment as in the main the deposits of northern currents, and derived from Arctic land, and that like the great banks of the American coast at the present day, which are being built up by the present Arctic current, they had little to do with any direct drainage from the adjacent shore. We need not deny, however, that such ridges of Jand as existed along the Atlantic margin: were contributing their quota of river-borne material, just as on a still greater scale the Amazon and Mississippi are doing now, and this especially on the sides toward the present continentai plateaus, though the greater part must have been derived from the wide tracts of Laurentian land within the Arctic Circle or near to it. It is further obvious that the ordinary reasoning respecting the necessity of continental areas in the present oceau basins would actually oblige us to suppose that the whole of the oceans and continents had repeatedly changed places. This consideration opposes enormous physical difficulties to any theory of alternations of the oceanic and continental areas, except locally at their margins. I would, however, refer yo: for a more full discussion of these points to the addiress to be delivered to-morrow by the President of the Geological Section.

But the permanence of the Atlantic depression does not ex clude the idea of successive submergences of the continental plateaus and marginal slopes, alternating with periods of elevation, when the ocean retreated from the continents and con tracted its limits. In this respect the Atlantic of to-day is much smaller than it was in those times when it spread widely over the continental plains and slopes, and much larger than it ha: been in times of continental elevation. This leads us to the further consideration that, while the ocean beds have been sinking, other areas have been better suppo:ted, and constitute th: continental plareaus; and that it has been at or near the junc tions of these sinking and rising areas that the thickest deposits of detritus, the most extensive foldings, and the greatest ejec tions of volcanic matter have occurred. There has thus been permanence of the position of the continents and oceans through out geological time, but with many oscillations of these areas, producing submergences and emergences of the land. In thi way we can reconcile the vast vicissitudes of the continental areas in different geological periods with that continuity of de velopment from north to south, and from the interiors to the margins, which is so marked a feature. $\mathrm{W}^{\top} \mathrm{e}$ have for this reason to formulate another apparent geological paradox, namely, that while in one sense the continental and oceanic areas are perma nent, in another they have been in continual movement. Nor does this view exclude extension of the continental borders or of chains of islands beyond their present limits, at certain periods and indeed the general principle already stated, that subsidence of the ocean bed has produced elevation of the land, implies in earlier periods a shallower ocean and many possibilities as to volcanic islands, and low continental margins creeping out into

I Among Anerican geologists, Dana and Le Conte, though from som: what different premises. maintain continental permanence. Crosby has argued on the other side. In Britain, Hull has elaborated the idea of interchange of oceanic and continental areas in his memoir in Trans. Dubii Society, and in his work entitled "The Physical History of the British Islands." Godwin-Austen argues powerfulty for the permanence of the At lantic basin, Q. J. Geol. Soc. vol. xii. p. 42. Mellard Reade ably advocate the theory of mutation. The two v.ews require, in my judgment, to be combined. More especially it is necessary to take into the account the existence of an Atlantic ridge of Laurentian rock on the west side of Europe, of which the Hebrides and the oldest rocks of Wales, Ireland, Western France, and Portugal are remuants. 
the sea; while it is also to be noted that there are, as already stated, bordering shelves, constituting shallows in the ocean, which at certain period's have emerged as land.

We are thus compelled to believe in the contemporaneous existence in all geological periods, except perhaps the earliest of them, of three distinct conditions of areas on the surface of the earth. (I) Oceanic areas of deep sea, which always continued to occupy in whole or in part the bed of the present ocean. (2) Continental plateaus and marginal shelves, existing as low flats or higher table-lands liable to periodical submergence and emergence. (3) Lines of plication and folding, more especially along the borders of the oceans, forming elevated portions of land, rarely altogether submerged, and constantly affording the material of sedimentary accumulations, while they were also the seats of powerful volcanic ejections.

In the successive geological periods the continental plateaus when submerged, owing to their vast extent of warm and shallow sea, have been the great theatres of the development of marine life and of the deposition of organic limestones, and when elevated they have furnished the abodes of the noblest land faunas and floras. The mountain belts, especially in the north, have been the refuge and stronghold of land life in periods of submergence, and the deep ocean basins have been the perennial abodes of pelagic and abyssal creatures, and the refuge of multitudes of other marine animals and plants in times of continental elevation. These general facts are full of importance with reference to the question of the succession of formations and of life in the geological history of the earth.

So much time has been occupied with these general views that it would be impossible to trace the history of the Atlantic in detail through the ages of the Palæozoic, Mesozoic, and Tertiary. We may, however, shortly glance at the changes of the three kinds of surface already referred to. The bed of the ocean seems to have remained on the whole abyssal, but there were probably periods when those shallow reaches of the Atlantic which stretch across its most northern portion, and partly separate it from the Arctic basin, presented connecting coasts or continuous chains of islands sufficient to permit animals and plants to pass over. ${ }^{1}$ At certain periors also there were not unlikely groups of volcanic islands, like the Azores, in the temperate or tropical Atlantic. More e pecially might this be the case in that early time when it was more like the present Pacific; and the line of the great volcanic belt of the Mediterranean, the mid-Atlantic banks, the Azores, and the IVest India Islands point to the posibility of such partial connections. These were stepping stones, so to speak, over which land organisms might cross, and some of these may be connected with the fabulous or prehistoric Atlantis. ${ }^{2}$

In the Cambrian and Ordovician periods the distinctions, already referred to, into continental plateaus, mountain-ridges, and ocean depths were first developed, and we find already great masses of sediment accumulating on the seaward sides of the old Laurentian ridges, and internal deposits thinning away from these ridges over the submerged continental areas, and presenting very dissimilar conditions of sedimentation. It would seem also that, as Hicks has argued for Europe, and Logan and Hall for America, this Cambrian age was one of slow subsidence of the land previously elevated, accompanied with or caused by thick deposits of detritus along the borders of the subsiding land, which was probably covered, with the decomposing rock arising from long ages of sub-aërial waste.

In the coal-formation age, its characteristic swampy flats stretched in some places far into the shallower parts of the ocean. ${ }^{3}$ In the Jurassic the American continent probably extended further to sea than at present. In the Wcalden age there was much land to the west and north of Great Britain, and Prof. Bonney has directed attention to the evidence of the existence of this land as far back as the Trias, while Mr. Starkie Gardner has insisted on connecting-links to the southward, as

\footnotetext{
I It would seem, from Geikie's description of the Faroe Islands, that they may be a remnant of such connecting land, dating from the Cretaceous or Eocene period.

${ }^{2}$ Dr. Wilson has recently argued that the Atlantis of tradition was really America, and Mr. Hyde Clark has associated this idea with the early dominance in Western Europe of the Iberian race, which Dawkins connects with the Neolithic and Bronze Ages of archæology. My own attention has recently been directed, through specimens presented to the McGill College Museum, to the remarkable resemblances in cranial characters, wampum, and other particulars, of the Guanches of the Canaries with aborigines of E i-tern Amer.ca - resemblances which cannot be accidental.

3 I have shown the evidence of this in the remnants of Carboniferous districts once more extensive on the Atlant ic coast of Nova Scotia and Cape Rreton ("Acadian Geol gy").
}

evidenced by fossil plants. So late as the post-Glacial, or early human period, large tracts now submerged formed portions of the continents. On the other hand, the internal plains of America and Europe were often submerged. Such submergences are indicated by the great limestones of the Palæozoic, by the chalk and its representative beds in the Cretaceous, by the Nummulitic formation in the Eocene, and lastly by the great Pleistocene submergence, one of the most remarkable of all, one in which nearly the whole northern hemisphere participated, and which was probably separated from the present time by only a few thousands of years. ${ }^{1}$ These submergences and elevations were not always alike on the two sides of the Atlantic. The Salina period of the Silurian, for example, and the Jurassic, show continental elevation in America not shared by Europe. The great subsidences of the Cretaceous and the Eocene were proportionally deeper and wider on the eastern continent, and this and the direction of the land being from north to south cause more ancient forms of life to survive in America. These elevations and submergences of the plateaus alternated with the periods of mountain-making plication, which was going on at intervals at the close of the Eozoic, at the beginning of the Cambrian, at the close of the Siluro-Cambrian, in the Permian, and in Europe and Western America in the Tertiary. The series of changes, however, affecting all these areas was of a highly complex character, and embraces the whole physical history of the geological ages.

We may note here that the unconformities caused by these movements and by subsequent denudation constitute what Le Conte has called "lost intervals," and one of the most important of which is supposed to have occurred at the end of the Eozoic. It is to be observed, however, that as every such movement is followed by a gradual sub,idence, the seeming loss is caused merely by the overlapping of the successive beds deposited.

We may also note a fact which I have long ago insisted on ("Acadian Geology," I 865), the regular pulsations of the continental areas, giving $u$; alternations in each great system of formations of deep-sea and shallow-water beds, so that the successive groups of formations may be divided into triplets of shallow-water, deep-water, and shallow-water strata, alternating in each period.

In referring to the ocean basins we should bear in mind that there are three of these in the northern hemisphere-the Arctic, the Pacific, and the Atlantic. De Rance has ably summed up the known facts as to Arctic geology, and more recently Dr. G. M. Dawson has prepared for the Royal Society of Canada a résumé and map of what is known of the geology of the Arctic basin (meeting of May I886; the paper is not yet published), in comparison with Canadian geology. From this it appears that this area presents from without inwards a succession of oller and newer formations from the Eozoic to the Tertiary, and that its extent must have been greater in former periods than at present, while it must have enjoyed a comparatively warm climate. The relations of its deposits and fossils are closer with those of the Atlantic than with those of the Pacific, as might be anticipated from its wider opening into the former. Blandford has recently remarked on the correspondence of the marginal deposits around the Pacific and Indian Oceans, ${ }^{2}$ and Dr. Dawson informs me that this is equally marked in comparison with the west coast of America, ${ }^{3}$ but these marginal areas have not yet gained much on the ocean. In the North Atlantic, on the other hand, there is a wide belt of comparatively modern rocks on both sides, more especially toward the south, and on the American side; but while there appears to be a perfect correspondence on both sides of the Atlantic and around the Pacific respectI The recunt surveys of the Falls of Niagara coincide with a great many
evidences to which $I$ have elsewhere ref rred in proving that the Pleistocene submergence of America and Europe came to an end $n>t$ more than ten thousand years ago, and was itself not of very great duration. Thus in thousand years ago, and was itself not of very great duration. Thus in
Pleistocene times the land must have been submerged and re-elevated in a very rapid manner.

A singular example is the recurrence in New Zealand of Trassic rocks and fossis of types corresponding to those of British Columbia. A curinus $\mathrm{m}$ dern analogy appears in the works of art of the Maoris with those of the Haida Indjans of the Queen Charlotte Islands, and both are eminently Pacific in contradistinction to Atlantic.

3 Journal of Geolugical Society, May r 885 . Blandford's statements respecting the mechanical deposits of the close of the Palæozoic in the Pacific area, whether these are glacial or not, would seem $t s$ show a correspondence with the Permian conglo.nerates and earth-movements of the Atlantic area; but since that time the Atlantic has enjoyed comparative repose. The Par ific also seems to have reproduced the conditions of the Carboniferous in the Cretaceous age, and seems to have been less affected by the great changes of the Pleistocene. 
ively, there secms to be less parallelism between the deposits and forms of life of the two oceans as compared with each other, and less correspondence in furms of life, especially in modern times. Still in the earlier geological ages, as might have been anticipated from the imperfect development of the continents, the same forms of life characterise the whole ocean from Australia to Arctic America, and indicate a grand unity of Pacific and Atlantic life not equalled in later times, ${ }^{1}$ and which speaks of contemporaneity rather than of what has been termed homotaxis.

We may pause here for a moment to notice some of the effects of Atlantic growth on modern geography. It has given us rugged and broken shores composed of old rocks in the north, and newer formations and softer features towards the south. It has given us marginal mountain-ridges and internal plateaus on both sides of the sea. It has produced certain curious and by no means accidental correspondences of the eastern and western sides. Thus the solid basis on which the British Islands stand may be compared with Newfoundland and Labrador, the English Channel with the Gulf of St. Lawrence, the Bay of Biscay with the Bay of Maine, Spain with the projection of the American land at Cape Hatteras, the Mediterranean with the Gulf of Mexico. The special conditions of deposition and plication necessary to these results, and their bearing on the character and productions of the Atlantic basin, would require a volume for their detailed elucidation.

Thus far our discussion has been limited almost entirely to physical causes and effects. If we now turn to the life-history of the Atlantic, we are met at the threshold with the question of climate, not as a thing fixed and immutable, but as changing from age to age in harmony with geographical mutations, and producing long eosmic summers and winters of alternate warmth and refrigeration.

We can scarcely doubt that the close connection of the Atlantic and Arctic Oceans is one factor in those remarkable vicissitudes of climate experienced by the former, and in which the Pacific area has also shared in connection with the Antarctic Sea. No yeological facts are indeed at first sight more strange and inexplicable than the changes of climate in the Atlantic area, even in comparatively modern periods. We know that in the early Tertiary perpetual summer reigned as far north as the middle of Greenland, and that in the Pleistocene the Arctic cold advanced, until an almost perennial winter prevailed, half-way to the equator. It is no wonder that nearly every cause available in the heavens and the tarth has been invoked to account for these astounding facts.

It will, I hope, meet with the approval of your veteran glaciologist, Dr. Crosskey, if, neglecting most of the-e theoretical views, I venture to invite your attention in connection with this question chiefly to the old Lyellian doctrine of the modification of climate by geographical changes. I.et us, at least, consider how much these are able to account for. ${ }^{2}$

The ocean is a great equaliser of extremes of temperature. It does this by its great capacity for heat and by its cooling and heating power when passing from the solid into the liquid and gaseous states, and the reverse. It also acts by its mobility, its currents serving to convey heat to great distances, or to cool the air by the movement of cold icy waters. The land, on the other hand, cools or warms rapidly, and can transmit its influence to a distance only by the winds, and the infuence so transmitted is rather in the nature of a disturbing than of an equalising cause. It follows that any change in the distribution of land and water must affect climate, more especially if it changes the character or course of the ocean currents. ${ }^{3}$

I Daintree and Etheridge, "Queensland Geology," Journal of Geological Society, August 1872; R Etheridge, Junior, "Australian Fossils," Trans. Phys. Soc., Edin.. r880.

${ }_{2}$ The late Mr. Searles V. Wood, in an able summary of the possible causes of the succession of cold and warm climates in the njrthern hemisphere, enumerates no fewer than seven theories which have met with more or less acceptance. These are:-

(I) The gradual cooling of the earth from a condition of original incandescence.

(2) Changes in the obliquity of the ecliptic.

(4) The effect of the precession of the equinoxes along with changes of the eccentricity of the earth's orbit.

(5) Variations in the amount of heat given off by the sun.

(6) Differences in the temperature of portions of space passed through by

(7) Differences in the distribution of land and water in connection with the flow of c ceanic currents.

3 Von Woeikeff has very strongly put these principles in a review of Croll's recent book, "Climate and Cosmology," American Fournal of Science, March 1886.
At the present time the North Atlantic presents some very peculiar, and in some respects exceptional, features, which are most instructive with reference to its past history. The great intern +1 plateau of the American continent is now dry land the passage across Central America between the Atlantic and Pacific is blocked; the Atlantic opens very widely to the north ; the high mass of Greenland towers in its northern part. The effects are that the great equatorial current running across from Africa and embayed in the Gulf of Mexico, is thrown northward and eastward in the Gulf Stream, acting as a hot-water apparatus to heat up to an exceptional degree the western coast of Europe. On the other hand, the cold Arctic current from the Polar seas is throwil to the westward, and runs down from Greenland past the American shore. ${ }^{1}$ The pilot chart for June of this year shows vast fields of drift ice on the western side of the Atlantic as far south as the latitude of $40^{\circ}$. So far, therefore, the Glacial age in that part of the Atlantic still extends; this at a time when, on the eastern side of the Atlantic, the culture of cereals reaches in Norway beyond the Arctic Circle. Let us inquire into some of the details of these phenomena.

The warm water thrown into the North Atlantic not only increases the temperature of its whole waters, but gives an exceptionally mild climate to Western Europe. Still the countervailing infuence of the Arctic currents and the Greenland ice is sufficient to permit icebergs which creep down to the mouth of the Strait of Belle Isle, in the latitude of the south of England, to remain unmelted till the snows of a succeeding winter fall upon them. Now let us suppose that a subsidence of land in tropical America were to allow the equatorial current to pass through into the Pacific. The effect would at once be to reduce the temperature of Norway and Britain to that of Greenland and Labrador at present, while the latter countries would themselves become colder. The northern ice, drifting down into the Atlantic, would not, as now, be melted rapidly by the warm water which it meets in the Gulf Stream. Much larger quantities of it would remain undissolved in summer, and thus an accumulation of permanent ice would take place, along the American coast at first, but probably at length even on the European side. This would still further chill the atmosphere, glaciers would be established on all the mountains of temperate Europe and America, ${ }^{2}$ the summer would be kept coll by melting ice and snow, and at length all Eastern America and Europe might become uninhabitable, except by Arctic animals and plants, as far south as perhaps $40^{\circ}$ of north latitude. This would be simply a return of the Glacial age. I have assumed only one geographical change; but other and more complete cbanges of subsidence and elevation might take place, with effects on climate still more decisive; more especially would this be the case if there were a considerable submergence of the land in temperate latitudes.

We may suppose an opposite case. The high plateau of Greenland might subside, or be reduced in height, and the openings of Baffin's Bay and the North Atlantic might be closed. At the same time the interior plain of America might be depressed, so that, as we know to have been the case in the Cretaceous period, the warm waters of the Mexican Gulf would circulate as far north as the basins of the present great American lakes. In these circumstances there would be an immense diminution of the sources of floating ice, and a correspondingly vast increase in the surface of warm water. The effects would be to enable a temperate flora to subsist in Greenland, and to bring all the present temperate regions of Europe and America into a condition of subtropical verdure.

It is only neces:ary to add that we know that vicissitudes not dis-imilar from those above sketched have actually occurred in comparatively recent geological times, to enable us to perceive that we can dispense with all other causes of change of climate, though admitting that some of them may have occupied a secondary place. ${ }^{3}$ 'This will give us, in dealing with the distribution of life, the great advantage of not being tied up to definite astronomical cycles of glaciation, which may not always stit the geological facts, and of correlating elevation and subsidence of the land with changes of climate affecting living beings. It

I I may refer here to the admirable expositions of these effects by th late Dr. Carpenter in his papers on the results of the explorations of the Challenger.

According to Bonney, the west coast of Wales is about $12^{\circ}$ above the average for its latitude, and if reduced to $12^{\prime}$ below the average its moun tains would have large glacier.

More especially the ingenious and elaborate arguments of Croll deserv consideration; and, though I cannot agree with him in his main thesis, I gladly acknowledge the great utility of the work he has done. 
will, however, be necessary, as Wallace well insists, that we shall hold to that dégree of fixity of the continents in their position, notwithstanding the submergences and emergences they have experienced, to which I have already adverted. Sir Charles Lyell, more than forty years ago, published in his "Principles of Geology" two imaginary maps which illustrate the extreme effects of various distribution of land and water. In one all the continental masses are grouped around the equator. In the other they are all placed around the poles, leaving an open equatorial ocean. In the one case the whole of the land and its inhabitants would enjoy a perpetual summer, and scarcely any ice could exist in the $s \div a$. In the other the whole of the land would be subjected to an Arctic climate, and it would give off immense quantities of ice to cool the ocean. But Lyell did not suppose that any such distribution as that represented in his maps had actually occurred, though this supposition has been sometimes attributed to him. He merely put what he regarded as an extreme case to illustrate what might occur under conditions less exaggerated. Sir Charles, like other thoughtful geologists, was well aware of the general fixity of the areas of the continents, though with great modifications in the matter of submergence and of land conditions. The union, indeed, of these two great principles of fixity and diversity of the continents lies at the foundation of theoretical geology.

We can now more precisely indicate this than was possible when Lyell produced his "Principles," and can reproduce the conditions of our continents in even the more ancient periods of their history. Some examples may be taken from the history of the American continent, which is more simple in its arrangements than the double continent of Europ-asia. We may select the early Devonian or Erian period, in which the magnificent flora of that age-the earliest certainly known to usmade its appearance. Imagine the whole interior plain of North America submerged, so that the continent is reduced to two strips on the east and west, connected by a belt of Laurentian land on the north. In the great mediterranean sea thus produced, the tepid water of the equatorial current circulated, and it swarmed with corals, of which we know no less than 150 species, and with other forms of life appropriate to warm seas. On the islands and coasts of this sea was introduced the Erian flora, appearing first in the north; and with that vitality and colonising power of which, as Hooker has well shown, the Scandinavian flora is the best modern type, spreading itself to the south. ${ }^{1}$ A very similar distribution of land and water in the Cretaceous age gave a warm and equable climate in those portions of North America not submerged, and coincided with the appearance of the multitude of broad-leaved trees of modern types introduced in the early and middle Cretaceous, and which prepared the way for the mammalian life of the Eocene. We may take a still later instance from the second continental period of the later Pleistocene or early modern, when there would seem to have been a partial or entire closure of the North Atlantic against the Arctic ice, and wide extensions seaward of the European and American land, with possibly considerable tracts of land in the vicinity of the equator, while the Mediterranean and the Gulf of Mexico were deep inland lakes (Dawkins, Popular Science Monthly, 1873). The effect of such conditions on the climates of the northern hemisphere must have been prodigious, and their investigation is rendered all the more interesting because it would seem that this continental period of the post-Glacial age was that in which man made his first acquaintance with the coasts of the Atlantic, and possibly made his way across its waters.

We have in America ancient periods of cold as well as of warmth. I have elsewhere referred to the boulder conglomerates of the Huronian, of the Cambrian and Ordovician, of the Millstone-grit period of the Carboniferous and of the early Permian, but would not venture to affirm that either of these periods was comparable in its cold with the later Glacial age, still less with that imaginary age of continental glaciation assumed by certain of the more extreme theorists ("Notes on Post-Pliocene of Canada"; "Pre-Cambrian Glaciers," Geol. Mag., 1880). These ancient conylomerates were probably produced by floating ice, and this at periods when in areas not very remote temperate floras and faunas could flourish. The glacial periods of our old continent occurred in times when the surface

I As I have elsewhere endeavoured to show ("Report on Silurian and Devonian Plants of Canada"), a warm climate in the Arctic region seems to have afforded the necessary conditions for the great colonising floras of all geological periois. Gray had previously illustrated the same fact in the case of the more modern floras. of the submerged land was opened up to the northern currents, drifting over it mud and sand and stones, and rendering nugatory, in so far at least as the bottom of the saa was concerned, the effects of the superficial warm streams. Some of these beds are also peculiar to the eastern margin of the continent, and indicate ice-drift along the Atlantic coast in the same manner as at present, while conditions of greater warmth existed in the interior. Even in the more recent Glacial age, while the mountains were covered with snow and the lowlands submerged under a sea laden with ice, there were interior tracts in somewhat high latitudes of America in which hardy forest trees and herbaceous plants flourished abundantly; and these were by no means exceptional "interglacial" pe-iods. Thus we can show that, while from the remote Huronian period to the Tertiary the American land occupied the same position as at present, and while its changes were merely change; of relative level as compared with the sea, these have so influenced the ocean currents as to cause great vicissitudes of climate.

Without entering on any detailed discussion of that last and greatest Glacial period which is best known to us, and is more immediately connected with the early history of man and the modern animals, it may be proper to make a few general statements bearing on the relative importance of sea-borne and land ice in producing those remarkable phenomena attributable to ice action in this period. In considering this question it must be borne in mind that the greater masses of floating ice are produced at the seaward extremities of land glaciers, and that the heavy field-ice of the Arctic regions is not so much a result of the direct freezing of the surface of the sea as of the accumulation of snow precipitated on the frozen surface. In reasoning on the extent of ice action, and especially of glaciers in the Pleistocene age, it is necessary to keep this fully in view. Now in the formation of glaciers at present-and it would seem also in any conceivable former state of the earth-it is necessary that extensive evaporation should conspire with great condensation of water in the solid form. Such conditions exist in mountainous regions sufficiently near to the sea, as in Greenland, Norway, the Alps, and the Himalayas ; but they do not exist in low Arctic lands like Siberia or Grinnell Land, nor in inland mountains. It follows that land-glaciation has narrow limits, and that we cannot assume the possibility of great confluent or continental glaciers covering the interior of wide tracts of land. No imaginable increase of cold could render this possible, inasmuch as there could not be a sufficient influx of vapour to pro: duce the necessary condensation; and the greater the cold, the less would be the evaporation. On the other hand, any increass of heat would be felt more rapidly in the thawing and evaporation of land ice and snow than on the surface of the sea.

Applying these very simple geographical truth; to the North Atlantic continents, it is easy to perceive that no amount of refrigeration could produce a continental glacier, because there could not be sufficient evaporation and precipitation to afford the necessary snow in the interior. The case of Greenland is often referred to, but this is the case of a high mass of cold land with sea, mostly open, on both sides of it, giving, therefore, the conditions most favourable to precipitation of snow. If Greenland were less elevated, or if there were dry plains around it, the case would be quite different, as Nares has well shown by his observations on the summer verdure of Grinnell Land, which, in the immediate vicinity of North Greenland, presents very different conditions as to glaciation and climate. ${ }^{1}$ If the plains were submerged, and the Arctic currents allowed free access to the interior of the continent of America, it is conceivable that the mountainous regions remaining out of water would be covered with snow and ice, and there is the best evidence that this actually occurred in the Glacial period; but with the plains out of water this would be impossible. We see evidence of this at the present day in the fact that in unusually cold winters the great precipitation of snow takes place south of Canada, leaving the north comparatively bare, while as the temperature becomes milder the area of snow deposit moves farther to the north. Thus a greater extension of the Atlantic, and especially of its cold ice-laden Arctic currents, becomes the most potent cause of a glacial age.

I have long maintained these conclusions on general geographical grounds, as well as on the evidence afforded by the Pleistocene deposits of Canada ; and in an address the theme of

- These views have been admirably illustrated by Von Woeikoff in the paper already referred to, and in previous geographical papers. 
which is the ocean I may be excused for continuing to regard the supposed terminal moraines of great continental glaciers as nothing but the southern limit of the ice-drift of a period of submergence. In such a period the southern margin of an iceladen sea where its floe-ice and bergs grounded, or where its ice was rapidly melted by warmer water, and where consequently its burden of boulders and other debris was deposited, would necessarily present the aspect of a moraine, whic 1 by the long continuance of such conditions might a ssume gigantic dimensions. Let it be observed, however, that I fully admit the evidence of the great extension of local glaciers in the Pleistocene age, and especially in the times of partial submergence of the land.

I am quite aware that it has been held by many able American geologists ${ }^{1}$ that in North America a continental glacier extended in temperate latitudes from sea to sea, or at least from the Atlantic to the Rocky Mountains, and that this glacier must, in many places, have exceeded a mile in thickness. The reasons above stated appear, however, suficient to compel us to seek for some other explanation of the observed facts, however diffcult this may at first sight appear. With a depression such as we know to have existed, admitting the Arctic currents along the St. Lawrence Valley, through gaps in the Laurentian watershed, and down the great plains between the Laurentian areas and the Rocky Mountains, we can easily understand the covering of the hills of Eastern Canada and New England with ice and snow, and a similar covering of the mountains of the west coast. The sea also in this case might be ice-laden and boulder-bearing as far south as $40^{\circ}$, while there might still be low islands far to the north on which vegetation and animals continued to exist. We should thus have the conditions necessary to explain all the anomalies of the glacial deposits. Even the glaciation of high mountains south of the St. I awrence Valley would then become explicable by the grounding of floeice on the tops of these mountains when reefs in the sea. In like manuer we can understand how on the isolated trappean hill of Belœil, in the St. Lawrence Valley, Laurentian boulders far removed from their native seats to the north are perched at a height of about I 200 feet on a narrow peak where no glacier could possibly have left them. The so-called moraine, traceable from the great Missouri Coteau in the west to the coasts of New Jersey, would thus become the mark of the western and southern limit of the subsidence, or of the line along which the cold currents bearing ice were abruptly cut off by warm surface waters. I am glad to find that these considerations are beginning to have weight with European geologists in their explanation of the glacial drift of the great plains of Northern Europe.

Whatever difficulties may atten 1 such a supp ssition, they are small compared with those attendant on the belief of a continental glacier, moving without the aid of gravity, and depending for its material on the precipitation taking place on the interior plains of a great continent.

I have elsewhere endeavoured to show, on the evidence found in Canada, that the occurrence of marine shells, land plants, and insects in the glacial deposits of that country indicates not so much the effect of general interglacial periods as the local existence of conditions like those of Grinnell Land and Greenland, in proximity to each other at one and the same period, and depending on the relative levels of land and the distribution of ocean currents and ice-drift. ${ }^{2}$

I am old enough to remember the sensation caused by the delightful revelations of Edward Forbes respecting the zones of animal life in the sea, and the vast insight which they gave into the significance of the work on minute organisms previously done by Ehrenberg, Lonsdale, and Williamson, and into the meaning of fossil remains. A little later the soundings for the Atlantic cable revealed the chalky foraminiferal ooze of the abyssal ocean ; still more recently the wealth of facts disclosed by the Challenger voyage, which naturalists have not yet had time to digest, have opened up to us new worlds of deep-sea life.

The bed of the deep Atlantic is covered for the most part by a mud or ooze largely made up of the debris of Foraminifera and other minute organisms mixed with fine clay. In the North Atlantic the Norwegian naturalists call this Biloculina mud. Further south the Challenger naturalists speak of it as Globigerina

\footnotetext{
I Report of Mr. Carvill Lewis in "Pennsylvania Geslogical Survey," r\$84; also Dana's " Manual. $"$ "Notes on Post-Ptiocene of Canada," 1872 . One well-marked interval
only has been established in the glacial deposits of Canada.
}

ooze. In point of fact it contains different species of foraminiferal shells, Globigerina and Orbulina being in some localities dominant, and in others other species, and these changes are more apparent in the shallower portions of the ocean.

It is also to be observed that there are means for disseminating coarse material over the ocean bed. There are in the line of the Arctic current on the American coast great sand-banks, and off the coast of Norway sand constitutes a considerable part of the bottom material. Soundings and dredgings off Great Britain, and also off the American coast, have shown that fragments of stone referable to Arctic lands are abundantly strewn over the bottom along certain lines, and the Antarctic continent, otherwise almost unknown, makes its presence felt to the dredge by the abundant masses of crystalline rock drifted far from it to the north. These are not altogether new discoveries. I had inferred many years ago, from stones taken up by the hooks of fishermen on the banks of Newfoundland, that rocky material from the north is dropped on these banks by the heavy ice which drifts over them every spring, that these stones are glaciated, and that after they fall to the bottom sand is drifted over them with sufficient velocity to polish the stones and to erode the shelly coverings of Arctic animals attached to the m ("Notes on Post-Pliocene of Canada," 1872). If then the Atlantic basin were upheaved into land we should see beds of sand, gravel, and boulders with clay flats and layers of marl and limestone. According to the Challenger Reports, in the Antarctic seas south of $64^{\circ}$ there is blue mud with fragments of rock in depths of 1200 to 2000 fathoms. The stones, some of them glaciated, were granite, diorite, amphibolite, mica-schist, gneiss, and quartzite. This deposit ceases and gives place to Globigerina ooze and red clay at $46^{\circ}$ to $47^{\circ} \mathrm{S}$., but even further north there is sometimes as much as 49 per ceat. of crystalline sand. In the Labrador current a block of syenite weighing 490 pounds was taken up from $\mathbf{I} 340$ fathoms, and in the Arctic current, 100 miles from land, was a stony deposit, some stones being glaciated. Among these were smoky quartz, quartzite, limestone, dolomite, mica-schist, and serpentine; also particles of monoclinic and triclinic feldspar, hornblende, augite, magnetite, mica, and glauconite, the latter no doubt formed in the seabottom, the others drifted from Eozoic and Palæozoic formations to the north ("General Report, Challenger Expedition").

A remarkable fact in this connection is that the great depths of the sea are as impassable to the majority of marine animals as the land itself. According to Murray, while twelve of the Challenger's dredgings taken in depths greater than 2000 fathoms gave 92 species, mostly new to science, a similar number of dredgings in shallower water near the land gave no less than Iooo species. Hence arises another apparent paradox relating to the distribution of organic beings. While at first sight it might seem that the chances of wide distribution are exceptionally great for marine species, this is not so. Except in the case of those which enjoy a period of free locomotion when young, or are floating and pelagic, the deep ocean sets bounds to their migrations. On the other hand, the spores of cryptogamic plants may be carried for vast distances by the wind, and the growth of volcanic islands may effect connections which, though only temporary, may afford opportunity for land animals and plants to pass over.

But I must here call your attention to still another geological paradox, namely, that the deep sea, which is so great a barrier to the passage of the shallow-water animals, seems, under certain conditions, to afford facilities for the transmission of land animals and plants. The connections established by the observations of the Challenger, and so well expounded by Wallace and Hemsley ("Continental and Island Life"; "Botany of the Challenger Expedition"), between the floras of oceanicislands and the continents, establish this conclusively. Thus the Bermudas, altogether recent islands, have been stocked by the agency chiefly of the ocean currents and of birds, with nearly 150 species of continental plants, and the facts collected by Hemsley as to the present facilities of transmission, along with the evidence afforded by older oceanic islands which have been receiving animal and vegetable colonists for longer periods, go far to show that, time being given, the sea actually affords facilities for the migrations of the inhabitants of the land, greater than those of continuous continents.

With reference to the transmission of living beings across the Atlantic, we have before us the remarkable fact that from the Cambrian age onwards there were on the two sides of the ocean many species of invertebrate animals which were either 
identical or so closely allied as to be possibly varietal forms. ${ }^{1}$ In like manner the early plants of the Upper Silurian, Devonian, and Carboniferous present many identical species; but this identity becomes less marked in the vegetation of the more modern times.

In so far as plants are concerned, it is to be observed that the early forests were largely composed of cryptogamous plants, and the spores of these in modern times have proved capable of transmission for great distance. In considering this we cannot fail to conclude that the union of simple cryptogamous fructification with arboreal stems of high complexity, so well illustrated by Dr. Williamson, had a direct relation to the necessity for a rapid and wide distribution of these ancient trees. It seems also certain that some spores, as, for example, those of the Rhizocarps (see paper by the author on "Palæozoic Rhizocarps," Chicago Tiransactions, I886), a type of vegetation abundant in the Palæoz sic, and certain kinds of seeds, as tho e named AEtheotesta and Pachytheca, were fitted for flotation. Further, the periods of Arctic warmth permitted the passage around the northern belt of many temperate species of plants, just as now happens with the Arctic flora; and when these were disperse 3 by colder periods they marched southward along both sides of the sea on the mountain-chains.

The same remark applies to northern forms of marine invertebrates, which are much more widely distributed in longitude than those further south. The late Mr. Gwyn Jeffreys, in one of his latest communications to this Association, stated that 54 per cent. of the shallow-water mollusks of New England and Canada are also European, and of the deep-sea forms 30 out of 35 ; these last of course enjoying greater facilities for misration than those which have to travel slowly along the shallows of the coasts in order to cross the ocean and settle themselves on both sides. Many of these animals, like the common mussel and sand clam, are old settlers which came over in the Pleistocene period, or even earlier. Others, like the common periwinkle, seem to have been slowly extending themselves in modern times, perhaps even by the agency of man. The older immigrants may possibly have taken advantage of lines of coast now submerged, or of warm periods, when they could creep around by the Arctic shores. Mr. Herbert Carpenter and other naturalists employed on the Challenger collections have made similar statements respecting other marine invertebrates, as, for instance, the Echinoderms, of which the deep-sea crinoids present many common species, and my own collections prove that many of the shallow-water forms are common. Dall ("Report on Alaska") and Whiteaves (Transactions R. S. C.) have hown that some mollusks and Echinoderms are common even to the Atlantic and Pacific coasts of North America; a remarkable fact, tes ifying at once to the fixity of these species and to the manner in which they have been able to take advantage of geographical changes. Some of the species of whelks common to the Gulf of St. Lawrence and the Pacific are animals which have no special locomotive powers even when young, but they are northern forms not proceeding far south, so that they may have passed through the Arctic seas. In this connection it is well to remark that many species of animals have powers of locomotion when young which they lose when adult, and that others may have special means of transit. I once found at Gaspé a specimen of the Pacific species of Coronula, or whale-barnacle, the C. regine of Darwin, attached to a whale taken in the Gulf of St. Lawrence, and which had probably succeeded in making that passage around the north of America which so many navigators have essayed in vain.

It is to be remarked here that while many plants and marine invertebrates are common to the two sicles of the Atlantic, it is different with land animals, and especially vertebrates. I do not know that any fossil insects or land-snails or millipedes of Europe and America are specifically identical, and of the numerous species of batrachian: of the Carboniferous and reptiles of the Mesozoic all seem to be distinct on the two sides. The same appears to be the case with the Tertiary mammals, until in the later stages of that great period we find such genera as the horse, the camel, and the elephant appearing on the two sides of the Atlantic; but eve, then the species seem different, except in the case of a few northern forms.

I See Davidson's "Munographs on Brachiopods"; Etheridge, "Address to Geological Society of Lond " "; Woorlward, "Address to Geologists" Association" ; also Barrande's "Special Memoirs on the Brachiopods, p rts on Canadian Fossils" ; and Matthews, "Cambrian' of New Brunswick," Trans. R.S.C.
Some of the Ionger-lived mollusks of the Atlantic furnish suggestions which remarkably illustrate the biological aspect of these questions. Our familiar friend the oyster is one of these. The first known oysters appear in the Carboniferous in Belgium and in the United States of America. In the Carboniferous and Permian they are few and small, and they do not culminate till the Cretaceous, in which there are no less than ninety-one socalled species in America alone; but some of the largest known species are found in the Eocene. The oyster, though an inhabitant of shallow water, and very limitedly locomotive when young, has survived all the changes since the Carboniferous age, and has spread itself over the whole northern hemisphere (White, "Report U.S. Geol. Survey, r882-83").

I have collected fossil oysters in the Cretaceous clays of the coulées of Western Canada, in the Lias shales of England, in the Eocene and Cretaceous beds of the Alps, of Egypt, of the Red Sea coast, of Judæa, and the heights of Lebanon. Everywhere and in all formations they present forms which are so variable and yet so similar that one might suppose all the so-called species to be mere varieties. Did the oyster originate separately on the two sides of the Atlantic, or did it cross over so promptly that its appearance seems to be identical on the two sides? Are all the oysters of a common arcestry, or did the causes, whatever they were, which introduced the oyster in the Carboniferous act over again in later periods? Who can tell? This is one of the cases where causation and development - the two scientific factors which constitute the basis of what is vaguely called evolution-cannot easily be isolated. I would recommend to those biologists who discuss these questions to addict themselves to the oyster. This familiar mollusk has successfully pursued its course and bas overcome all its enemies, from the flat-toothed selachians of the Carboniferous, to the oyster-dredgers of the present day, has varied almost indefinitely, and yet has continued to be an oyster, unless indeed it may at certain portions of its career have temporarily assumed the disguise of a Gryphea or an Exogyra. The history of such an animal deserves to be traced with care, and much curious information respecting it will be found in the report which I have cited.

But in these respects the oyster is merely an example of many forms. Similar considerations apply to all those Pliocene and Pleistocene mollusks which are found in the raised sea-bottoms of Norway and Scotland, on the top of Moel Tryfaen in Wales, and at similar great heights on the hills of America, many of which can be traced back to early Tertiary times, and can be found to have extended themselves all over the seas of the northern hemisphere. They apply in like manner to the ferns, the conifers, and the angiosperms, many of which we can now follow without even specific change to the Eocene and Cretaceous. They all show that the forms of living things are more stable than the lands and seas in which they live. If we were to adopt some of the modern ideas of evolution, we might cut the Gordian knot by supposing that, as like causes can produce like effects, these types of life have originated more than once in geological time, and need not be genetically connected with each other. But while evolutionists repudiate : uch an application of their doctrine, however natural and rational, it would seem that nature still more strongly repudiates it, and will not allow us to assume more than one origin for one specics. Thus the great question of geographical distribution remains in all its force, and, by still another of our geological paradoxes, mountains become ephemeral things in comparison with the delicate herbage which covers them, and seas are in their present extent but of yesterday when compared with the minute and feeble organisms that creep on their sands or swim in their waters.

The question remains, Has the Atlantic achieved its destiny and finished its course, or are there other changes in store f.or it in the future? The earth's crust is now thicker and stronger than ever before, and its great ribs of crushed and folded rock are more firm and rigid than in any previous period. The stupendous volcanic phenomena manifested in Mesozoic and early Tertiary times along the borders of the Atlantic have apparently died out. These facts are in so far guarantees of permanence. On the other hand, it is known that movements of elevation along with local depression are in progress in the Arctic regions, and a great weight of new sediment is being deposited along the borders of the Atlantic, especially on its western side, and this is not improbably connected with the earthquake shocks and slight movements of depression which have occurred in North America. It is possible that these slow and secular movements may go on uninterruptedly until 
considerable changes are produced; but it is quite as likely that they may be retarded or reversed.

It is possible, on the other hand, that after the long period of quiescence which has elapsed there may be a new settlement of the ocean bed, accompanied with foldings of the crust, especially on the western side of the Atlantic, and possibly with renewed volcanic activity on its eastern margin. In either case a long time relatively to our limited human chronology may intervene before the occurrence of any marked change. On the whole, the experience of the past would lead us to expect movements and eruptive discharges in the Pacific rather than in the Atlantic area. It is therefore not unlikely that the Atlantic may remain undisturbed, unless secondarily and indirectly, until after the Pacific area shall have attained to a greater degree of quiescence than at present. But this subject is one too much involved in uncertainty to warrant us in following it further.

In the meantime the Atlantic is to us a practically permanent ocean, varying only in its tides, its currents, and its winds, which science has already reduced to definite laws, so that we can use if we cannot regulate them. It is ours to take advantage of this precious time of quietude, and to extend the blessings of science and of our Christian civilisation from shore to shore until there shall be no more sea, not in the sense of that final drying-up of old Ocean to which some physicists look forward, but in the higher sense of its ceasing to be the emblem of unrest and disturbance, and the cause of isolation.

I must now close this address with a short statement of the general objects which I have had in view in directing your at. tention to the geological development of the Atlantic. We cannot, I think, consider the topics to which I have referred without perceiving that the history of ocean and continent is an example of progressive design, quite as much as that of living beings. Nor can we fail to see that, while in some important directions we have penetrated the great secret of Nature, in reference to the general plan and structure of the earth and its waters, and the changes through which they have passed, we have still very much to learn, and perhaps quite as much to unlearn, and that the future holds out to us and to our successors higher, grander, and clearer conceptions than those to which we have yet attained. The vastness and the might of Ocean, and the manner in which it cherishes the feeble $t$ and most fragile beings, alike speak to us of Him who holds it in the hollow of $\mathrm{H}$ is hand, and gave to it of old its boundaries and its laws; but its teaching ascends to a higher tone when we consider its origin and history, and the manner in which it has been made to build up continents and mountain-chains, and at the same time to nourish and sustain the teeming life of sea and land.

\section{SECTION A}

\section{MATHEMATICAL AND PHYSICAL SCIENCE}

Opening Address by Prof. G. H. Darwin, M.A., Ll.D., F.R.S., F.R.A.S., President of the Section

A MERE catalogue of facts, however well arranged, has never led to any important scientific generalisation. For in any subject the facts are so numerous and many-sided that they only lead us to a conclusion when they are marshalled by the light of some leading idea. A theory is, then, a necessity for the advance of science, and we may regard it as the branch of a living tree, of which facts are the nourishment. In the struggle between competing branches to reach the light some perish, and others form vigorous limbs. And as in a tree the shape of the young shoot can give us but little idea of the ultimate form of the branch, so theories become largely transformed in the course of their existence, and afford in their turn the parent stem for others.

The success of a theory may be measured by the extent to which it is capable of assimilating facts, and by the smallness of the change which it must undergo in the process. Every theory which is based on a true perception of facts is to some extent fertile in affording a nucleus for the aggregation of new observations. $\Lambda \mathrm{nd}$ a theory, apparently abandoned, has often ultimately appeared to contain an element of truth, which receives acknowledgment by the light of later views.

It will, I think, be useful to avail myself of the present occasion to direct your attention to a certain group of theories which are still in an undeveloped and somewhat discordant condition, but which must form the nucleus round which many observations hive yet to be collected before these theories and their descend- ants can make a definitely accepted body of truth. If I am disposed to criticise some of them in their actual form, I shall not be understood as denying the great service which has been rendered to science by their formulation.

Great as have been the advances of geology during the present century, we have no precise knowledge of one of its fundamental units. The scale of time on which we must suppose geological history to be drawn is important not only for geology itself, but it has an intimate relation with some of the profoundest questions of biology, physics, and cosmogony.

We can hardly hope to obtain an accurate measure of time from pure geology, for the extent to which the events chronicled in strata were contemporaneous is not written in the strata them. selves, and there are long intervals of time of which no record has been preserved.

An important step has been taken by Alfred Tylor, Croll, and others, towards the determination of the rate of action of geological agents (Geikie, "Text-book of Geology," I882, p. 442). From estimates of the amount of sediment carried down by rivers, it appears that it takes from 1000 to 6000 years to remove one foot of rock from the general surface of a river basin.

From a consideration of the denuding power of rivers, and a measurement of the thickness of stratified rock, Phillips has made an estimate of the period of time comprised in geological history, and finds that, from stratigraphical evidence alone, we may regard the antiquity of life on the earth as being possibly between 38 and 96 millions of years ("Life on the Earth," Rede Lecture, I860, p. I I9)

Now while we should perhaps be wrong to pay much attention to these figures, yet at least we gain some insight into the order of magnitude of the periods with which we have to deal, and we may feel confident that a million years is not an infinitesimal fraction of the whole of geological time.

It is hardly to be hoped, however, that we shall ever attain to any very accurate knowledge of the geological time scale from this kind of argument.

But there is another theory which is precise in its estimate, and which, if acceptable from other points of view, will furnish exactly what is requisite. Mr. Croll claims to prove that great changes of climate must be brought about by astronomical events of which the dates are known or ascertainable ("Climate and Time"). The perturbation of the planets causes a secular variability in the eccentricity of the earth's orbit, and we are able confidently to compute the eccentricity of many thousands of years forward and backward from to-day, al hough it appears that, in the opinion of Newcomb and Adams, no great reliance can be placed on the values deduced from the formulæ at dates so remote as those of which Mr. Croll speaks. According to $\mathrm{Mr}$. Croll, when the eccentricity of the earth's orbit is at its maximum, that hemisphere which has its winter in aphelion would undergo a glacial period. Now, as the date of great eccentricity is ascertainable, this would explain the great Ice Age and give us it; date.

The theory has met with a cordial acceptance on many sides, probably to a great extent from the charm of the complete answer it affords to one of the great riddles of geology.

Adequate criticism of Mr. Croll's views is a matter of great difficulty on account of the diversity of causes which are said to co-operate in the glaciation. In the case of an effect arising from a number of causes, each of which contributes its share, it is obvious that if the amount of each cause and of each effect is largely conjectural the uncertainty of the total result is by no means to be measured by the uncertainty of each item, but is enormously augmented. Without going far into details it may be said that these various concurrent causes result in one fundamental proposition with regard to climate, which must be regarded as the keystone of the whole argument. That proposition amounts to this-that climate is unstable.

Mr. Croll holds that the various causes of change of climate operate inter se in such a way as to augment their several efficiencies. Thus the trade-winds are driven by the difference of temperature between the frigid and torrid zones, and if from the astronomical cause the northern hemisphere becomes cooler the trade-winds on that hemisphere encroach on those of the other, and the part of the warm oceanic current which formerly flowed into the cold north zone, will be diverted into the southern hemisphere. Thus the cold of the northern hemisphere is augmented, and this in its turn displaces the trade-winds further, and this again acts on the ocean currents, and so on; and this is neither more nor less than instahility. 
But if climate be unstable, and if, from some of those temporary causes for which no reasons can as yet be assigned, there acurs a short period of cold, then surely some even infinitesimal portion of the second link in the chain of causation must exist; and this should proceed as in the first case to augment the departure from the original $\mathrm{c}$ ondition, and the climate must change.

In a matter so complex as the weather, it is at least possible that there should be instability when the cause of disturbance is astronomical, whilst there is stability in an ordinary sense. If this is so, it might be explained by the necessity for a prolonged alteration in the direction of prevailing winds in order to affect oceanic currents (Zöppritz, Phil. Mag. 1878).

However this may be, so remarkable a doctrine as the instability of climate must certainly be regarded with great suspicion, and we should require abundant proof before accepting it. Now there is one result of Mr. Croll's theory which should afford almost a crucial test of its acceptability. In consequence of the precession of the equinoxes the conditions producing glaciation in one hemisphere must be transferred to the other every Io, 0oo years. If there is good geological evidence that this has actually been the case, we should allow very great weight to the astronomical theory, notwithstanding the difficulties in its way. Mr. Croll has urged that there is such evidence, and this view has been recently strongly supported by M. Blytt (NATURE, July 8 and 15,1886$)$. Other geologists do not, however, seem convinced of the conclusiveness of the evidence.

Thus Mr. Wallace ("Island Life"), whilst admitting that there was some amelioration of climate from time to time auring the last glacial period, cannot agree in the regular alternations of cold and warm demanded by Mr. Croll's theory. To meet this difficulty he proposes a modification. According to his view, large eccentricity in the earth's orbit will only produce glaciation when accompanied by favourable geographical conditions. And when extreme glaciation has once been established in the hemisphere which has its winter in aphelion, the glaciation will persist, with some diminution of intensity, when precession has brought round the perihelion to the winter. In this case, according to Wallace, glaciation will be simultaneous on both hemispheres.

Again, he contends that, if the geographical conditions are not favourable, astronomical causes alone are not competent to produce glaciation.

There is agreement between the two theories in admitting instability of climate at first, when glaciation is about to begin under the influence of great eccentricity of the orbit, but afterwards Wallace demands great stability of climate. Thus he maintains that there is great stability in extreme climates, either warm or cold, whil.t there is instability in moderate climates. I cannot perceive that we have much reason from physical considerations for accepting these remarkable propositions, and the acceptance or rejection of them demands an accurate knowledge of the most nicely balanced actions, of which we have as yet barely an outline.

Ocean currents play a most prominent part in these theories, but at this moment our knowledge of the principal oceanic circulation, and of its annual variability, is very meagre. In the course of a few years we may expect a considerable accession to our knowledge, when the Meteorological Office shall have completed a work but just begun - viz. the analysis of ships' loys for some sixty years, for the purpose of laying down in charts the oceanic currents.

With regard to the great atmospheric currents even the general scheme is not yet known. Nearly thirty years ago Prof. James Thomson gave before this Association at Dublin an important suggestion on this point. As it has been passed over in complete silence ever since, the present seems to be a good opportunity of redirecting attention to it.

According to Halley's theory of atmospheric circulation, the hot air rises at the equator and floats north and south in two grand upper currents, and it then acquires a westward motion relatively to the earth's surface, in consequence of the earth's rotation. Also the cold air at the pole sinks and spreads out over the earth's surface in a southerly current, at first with a westerly tendency, because the air cones from the higher regions of the atmosphere, and afterwards due south, and then easterly, when it is left behind by the earth in its rotation.

Now Prof. Thomson remarks that this theory disagrees with fact in as far as that in our latitudes, the winds, though westerly, have a poleward tendency, instead of the reverse.

In the face of this discrepancy he maintains that " the great circulation already described does actually occur, but occurs subject to this modification, that a thin stratum of air on the surface of the earth in the latitudes higher than $30^{\circ}$-a stratum in which the inhabitants of those latitudes have their existence, and of which the movements constitute the observed winds of those latitudes-being, by friction and impulses on the surface of the earth, retarded with reference to the rapid whirl or vortex-motion from west to east of the great mass of air above it, tends to flow towards the pole, and actually does so flow to supply the partial void in the central parts of that vortex due to the centrifugal force of its revolution. Thus it appears that in the temperate latitudes there are three currents at different heights - that the uppermost moves towards the pole, and is part of a grand primary circulation between equatorial and polar regions; that the lowermost moves also towards the pole, but is only a thin stratum forming part of a secondary circulation; that the middle current moves from the pole, and constitutes the return current for both the preceding; and that all these three currents have a prevailing motion from west to east" (Brit. Assoc. Report, Dublin, I857, pp. 38, 39).

Such, then, appears to be our present state of ignorance of these great terrestrial actions, and any speculations as to the precise effect of changes in the annual distribution of the sun's heat must be very hazardous until we know more precisely the nature of the thing changed.

When looking at the astronomical theory of geological climate as a whole, one cannot but admire the symmetry and beauty of the scheme, and nourish a hope that it may be true; but the mental satisfaction derived from our survey must not blind us to the doubts and difficulties with which it is surrounded.

And now let us turn to some other theories bearing on this important point of geological time.

Amongst the many transcendent services rendered to science by Sir William Thomson, it is not the least that he has turned the :earching light of the theory of energy on to the science of geology. Geologists have thus been taught that the truth must lie between the cataclysms of the old geologists and the uniformitarianism of forty years ago. It is now generally believed that we must look for a greater inten.ity of geologic action in the remote past, and that the duration of the geologic ages, howeve: little we may be able mentally to grasp their greatness, must bear about the same reiation to the numbers which were written down in the older treatises on geology, as the life of an ordinary man does to the age of Methuselah.

The arguments which Sir William Thomson has adduced in limitation of geological time are of three kinds. I shall refer first to that which has been called the argument from tidal friction; but before stating the argument itself it will be convenient to speak of the data on which the numerical results are based.

Since water is not frictionless, tidal oscillations must be subject to friction, and this is evidenced by the delay of twenty-four to thirty-six hours which is found to occur between full and change of moon and spring-tide. An inevitable result of this friction is that the diurnal rotati on of the earth must be slowly retarded, and that we who accept the earth as our timekeeper must accu e the moon of a secular acceleration of her motion round the earth, which cannot be otherwise explained. It is generally admitted by astronomers that there actually is such an unexplained secular acceleration of the moon's mean motion.

No passage in Thomson and Tait's "Natural Philosophy" has excited more general interest than that in which Adams is quoted as showing that, with a certain vxlue for the secular acceleration, the earth must in a century fall behind a perfect chronometer, set and rated at the beginning of the century, by twenty-two seconds. Unfortunately this passage in the first edition gave an erroneo:ts complexion to Adams's opinion, and being qusted without a statement of the premises, has been used in popular astronomy as an authority for establishing the statement that the earth is actually a false timekeeper to the precise amount specified.

In the second edition (in the editing of which I took part) this passage has been rewritten, and it is shown that Newcomb's estimate of the secular acceleration only gives about one third of the retardation of the earth's rotation, which resulted from Adams's value. The last sentence of the paragraph here runs as follows :- "It is proper to add that Adams lays but little stress on the actual numerical value; which have been used in this computation, and is of opinion that the amount of tidal retarda tion of the earth's rotation is quite uncertain." Thus, in the 
opinion of our great physical astronomer, a datum is still wanting for the determination of a limit to geological time, according to Thomson's argument.

However, subject to this uncertainty, with the values used by Adams in his computation, and with the assumption that the rate of tidal friction has remained constant, then a thousand million years ago the earth was rot ting twice as fast as at present. In the last edition of the "Natural Philosophy" the argument from these data runs thus:-

"If the consolidation of the earth took place then or earlier, the ellipticity of the upper layers (of the earth's mass) must have been $\frac{1}{230}$ instead of about $\frac{1}{30}$, as it is at present. It must necessarily remain uncertain whether the earth would from time to time adjust itself completely to a figure of equilibrium adapted to the rotation. But it is clear that a want of complete adjustment would leave traces in a preponderance of land in equatorial regions. The existence of large continents and the great effective rigidity of the earth's mass render it improbable that the adjustment, if any, to the appropriate figure of equilibrium would be complete. The fact, then, that the continents are arranged along meridians, rather than in an equatorial belt, affords some degree of proof that the consolidation of the earth took place at a time when the diurnal rotation differed but little from its present value. It is probable, therefore, that the date of consolidation is considerably more recent than a thousand million years ago."

I trust it may not be presumptnous in me to criticise the views of my great master, at whose intuitive perception of truth in physical questions I have often marvelled, but this passage does not even yet seem to me.to allow a sufficiently large margin of uncertainty.

It will be observed that the argument reposes on our certainty that the earth possesses rigidity of such a kind as to prevent its accommodation to the figure and arrangement of density appropriate to its rotation. In an interesting discussion on subaerrial denudation Croll has concluded that nearly one mile may have been worn off the equator during the past I2,000,000 years, if the rate of denudation all along the equator be equal to that of the basin of the Gange: ("Climate and Time," I885, p. 336). Now, since the equatorial protuberance of the earth when the ellipticity is $\frac{1}{3} \frac{1}{3}$ is fourteen miles greater than when it is $\frac{1}{500}$, it follows that $170,000,000$ years would suffice to wear down the surface to the equilibrium figure. Now let these numbers be halved r largely reduced, and the conclusion remains that denuciation would suffice to obliterate external evidence of some early excess of ellipticity.

If such external evidence be gone, we must rely on the incomparibility of the known value of the precessional constant with an ellipticity of internal strata of equal density greater than that appropriate to the actual ellipticity of the surface. Might there not be a considerable excess of internal ellipticity without our being c ignisant of the fact astronomically?

And, further, have we any right to feel so confident of the internal structure of the earth as to be able to allege that the earth would not through its whole mass adjust itself almost completely to the equilibrium figure?

Tresca has shown in his admirable memoirs on the flow of solids that when the : tresses rise above a certain value the solid becomes plastic, and is brought into what he calls the state of fluidity. I do not know, however, that he determined at what stage the flow ceases when the stresses are gradually diminished. It seems probable, at least, that flow will continue with smaller stresses than were initially necessary to start it. But if this is so, then, when the earth has come to depart both internally and externally from the equilibrium condition, a flow of solid will set in, and will continue until a near approach to the equilibrium condition is attained.

When we consider the abu : dant geological evidence of the plasticity of rock, and of the repeated elevation and subsidence of large areas on the earth's surface, this view appears to me more probable than Sir William Thomson's.

On the whole, then, I can neither feel the cogency of the argument from tidal friction itself, nor, accepting it, can I place any reliance on the limits which it assigns to geological history.

I I find by a rough calculation that $1 \frac{5 \pi}{50}$ ths of the land in the northern hemisphere are in the equatorial half of that hemisphere, viz. between $0^{\circ}$ and $30^{\circ} \mathrm{N}$. 'at. ; and that $\frac{t 6}{5}$ ths of the land in the southern hemisphere are in the equator.al half of that hemisphere, viz. between $0^{\circ}$ and $30^{\circ} \mathrm{S}$. lat. Thus for the whole earth, $\frac{1}{2} g \frac{1}{5}$ ths of all the land lie in the equatorial half of its surface, between $30^{\circ} \mathrm{N}$. and S. lat. In this computation the Mediterranean, Caspian, and Black Seas are treated as land.
The second argument concerning geological time is derived from the secular cooling of the earth.

We know in round numbers the rate of increase of temperature, or temperature gradient, in borings and mines, and the conductivity of rock. These data enable us to compute how long ago the surface must have had the temperature of melting rock, and when it must have been too hot for vegetable and animal life,

Sir William Thomson, in his celebrated essay on this subject (republished in Thomson and Tait's "Natural Philosophy,"Appendix D), concludes from this argument that "for the last $96,000,000$ years the rate of increase of temperature unclerground has gradually diminished from about ${ }_{1}^{1} \sigma^{\text {th }}$ th to about $\frac{1}{50}$ th of a degree Fahrenheit per foot. . . Is not this, on the whole, in harmony with geological evidence, rightly interpreted? Do not the vast masses of basalt, the general appearances of mountain-ranges, the violent distortions and fractures of strata, the great prevalence of metamorpluic action (which must have taken place at depths of not many miles, if so much), all agree in demonstrating that the rate of increase of temperature downwards must have been much more rapid, and in rendering it probable that volcanic energy, earthquake shocks, and every kind of so-called plutonic action, have been, on the whole, more abundantly and violently operative in geological antiquity than in the present age?"

Now, while I entirely agree with the general conclusion of Sir William Thomson, it is not unimportant to indicate a possible flaw in the argument. This flaw will only be acknowledged as possible by those who agree with the previous criticism on the argument from tidal friction.

The present argument as to the date of the consolidation of the earth reposes on the hypothesis that the earth is simply a cooling globe, and there are reasons why this may not be the case. The solidification of the earth probably began from the middle and spread to the surface. Now is it not possible, if not probable, that, after a firm crust had been formed, the upper portion still retained some degree of viscosity? If the interior be viscous, some tictal oscillations must take place in it, and, these being subject to friction, heat must be generated in the viscous portion; moreover the diurnal rotation of the earth must be retarded. Some years ago, in a paper on the tides of a spheroid, viscous throughout the whole mass (Phi'. Trans., part ii. 1879), I estimated the amount and distribution of the heat generated whilst the planet's rotation is being retarded and the satellite's distance is being increased. It then appeared that on that hypothesis the distribution of the heat must be such that it wo:ld only be possible to attribute a very small part of the observed temperature gradient to such a cause. Now, with a more probable internal constitution for the earth in early times, the result might be very different. Suppose, in fact, that it is only those strata which are within some hundreds of miles of the surface which are viscous, whilst the central portion is rigid. Then, when tidal friction does its work the same amount of heat is generated as on the hypothesis of the viscosity of the whole planet, but instead of being distributed throughout the whole mass, and principally towards the middle, it is now to be found in the more superficial layers.

In my paper it is shown that with Thomson's data for the conductivity of rock and the temperature gradient, the annual loss of heat by the earth is $1 / 260,000,000$ part of the earth's kinetic energy of rotation.

Also, if by tidal friction the day is reduced from $D_{0}$ hours to $D$ hours, and the moon's distance augmented from $\Pi_{0}$ to $\Pi$ earth's radii, the energy which has been converted into heat in the proces: is

$\left(\frac{D}{D_{0}}\right)^{2}-\mathrm{I}-8 \cdot 8+\left(\frac{\mathrm{I}}{\Pi}-\frac{\mathrm{I}}{\Pi_{0}}\right)$ times the earth's kinetic energy of rotation.

From these data it results that the heat generated in the lengthening of the day from twenty-three to twenty-four hours is equal to the amount of heat lost by the earth, at its present rate of loss, in $23,000,000$ years.

Now if this amount of heat, or any sensible fraction of it, was actually generated within a few hundred miles of the earth's surface, the temperature gradient in the earth must be largely due to it, instead of to the primitive heat of the mass.

Such an hypothesis precludes the assumption that the earth is simply a cooling mass, and would greatly prolong the possible extension of geological time. It must be observed that this view is not acceptable unless we admit that the earth can adjust itself to the equilibrium figure adapted to its rotation. 
It seems also worthy of suggestion that our data for the average giadient of temperature may be somewhat fallacious. Recent observations (Challenger Expedition) show that the lower stratun of the ocean is occupied by water at near the freezing temperature, whilst the mean annual temperature of the earth's surface, where the borings have been made, must be at least $30^{\circ}$ higher. It does not then seem impossible that the mean temperature gradient for the whole earth should differ sensibly from the mean gradient in the borings already made.

The foregoing remarks have not been made with a view of showing Sir William Thomson's argument from the cooling of the earth to be erroneous, but rather to maintain the scientific justice of assigning limits of uncertainty at the very least as wide as those given by him. Prof. Tait ("Recent Advances in Physical Science," I885) cuts the limit down to 10,000,000 years; he may be right, but the uncertainties of the case are fir too great to justify us in accepting such a narrowing of the conclusion.

The third line of argument by which a superior limit is sought for the age of the solar system appears by far the strongest. This argument depends on the amount of radiant energy which can have been given out by the sun.

The amount of work done in the concentration of the sun from a condition of infinite dispersion may be computed with some accuracy, and we have at least a rough idea of the rate of the sun's radiation. From these data Sir William Thomson concludes (Thomson and Tait, "Natural Philosophy," Appen$\operatorname{dix}$ E) :-

"It seems, therefore, on the whole most probable that the sun has not illuminated the earth for 100,000,000 years, and almost certain that he has not done so for $500,000,000$ years. As for the future, we may say, with equal certainty, that inhabitants of the earth cannot continue to enjoy the light and heat essential to their life for many million years longer unless sources now unknown to us are prepared in the great storehouse of creation."

This result is based on the value assigned by Pouillet and Herschel to the sun's radiation. Langley has recently made a fresh determination, which exceeds Pouillet's in the proportion of eight to five. ${ }^{1}$ With Langley's value Thomson's estimate of time would have to be reduced by the factor five-eighths.

It has been siggested by Croll that the primitive solar nebula may have been hot. This heat must have arisen from the collision of two or more masses; if their relative velocity before collision was that due simply to their mutual attraction, the heat so generated is already counted in the he th generated by the concentration of the sun fro $n$ a state of infinite dispersion. But if the relative velocity existed otherwise than from their mutual attraction, then the total heat in the sun might exceed that due simply to concentration. Sir William Thomson considers the hypothesis very improbable. The term imprubability seems, however, almost to lose its meaning in these speculations, and at leat we know by the spectroscope that actual nebulx do consist of incandescent gases.

In considering these three arguments I have adduced some reasons against the validity of the first argument, and have endeavoured to show that there are elements of uncertainty surrounding the other two; nevertheless they undoubtedly constitute a contribution of the first importance to physical geology. Whilst then we may protest against the precision with which Prof Tait seeks to deduce results from them, we are fully justified in following Sir William Thomson, who says that "the existing state of things on the earth, life on the earth, all geological history showing continuity of life, must be limited within some such period of past time as 100,000,000 years."

If I have carried you with me in this survey of theories bearing on geological time, you will agree that something has been acquired to our knowledge of the past, but that much more remains still to be determined.

Although speculation; as to the future course of science are usually of little avail, yet it seems as likely that meteorology and geology will pass the word of command to cosmical physics as the converse.

At present our knowledge of a definite limit to geological time has so little precision that we should do wrong to summarily

' Langley ( 1 nn. Res.R.A.S. $188_{5}$ ) estimates that 3 calories per minute are received by a square centimetre at distance unity. This gives for the total annual radiation of the sun $4.38 \times 10^{33}$ calories. Thomson gives as Pouillet's esimate $6 \times$ Io3 $^{\prime}$ times the heat required to raise $\mathrm{I}$ lb. of water $\mathrm{I}^{\circ} \mathrm{Cels}$., or $2^{2} 72 \times$ xo $^{33}$ calories. reject any theories which appear to demand longer periods of time than those which now appear allowable.

In each branch of science hypothesis forms the nucleus for the aggregation of observation, and as long as facts are assimilated and co ordinated we ought to follow our theory. Thus even if there be some inconsistencies with a neighbouring science we may be justified in still holding to a theory, in the hope that further knowledge may enable us to remove the difficulties. There is no criterion as to what degree of inconsistency should compel us to give up a theory, and it should be borne in mind that many views have been utterly condemned, when later knowledge has only shown us that we were in them only seeing the truth from another side.

\section{SECTION B}

CHEMICAL SCIENCE

Opening Address by William Crookes, F.R.S., V.P.C.S., PRESIDENT OF THE SECTION

A GLANCE over the Presidential addresses delivered before this Section on former occasions will show that the occupiers of this chair have ranged over a fairly wide field. Some of my predecessors have given a general survey of the progress of chemical science during the past year; some, taking up a technological aspect of the subject, have discussed the bearings of chemistry upon our national industries; others, again, have passed in review the various institutions in this country for teaching chemistry; and in yet other cases the speaker has had the opportunity of bringing before the scientific world, for the first time, an account of some impo:tant original researches.

On this occasion I venture to ask your attention to a few though $\mathrm{s}$ on the very foundations of chemistry as a science-on the nature and the probable, or at least possible, origin of the so-called elements. If the views to which I have been led may at first glance appear heretical, I must remind you that in some respects they are shared more or less, as I shall subsequently show, by not a few of the most eminent authorities, and notably by one of my predecessors in this chair, Dr. J. H. Gladstone, F.R.S., to whose brilliant address, delivered in 1883 , I must beg to refer you.

Should it not sometimes strike us, chemists of the present day, that after all we are in a position unpleasantly akin to that of our forerunners, the alchemists of the Middle Ages? These necromancers of a time long past did not, indeed, draw so sharp a line as do we between bodies simple and compound; yet their life-task was devoted to the formation of new combinations, and to the attempt to transmute bodies which we commonly consider as simple and ultimate--that is, the metals. In the department of synthesis they achieved very cunsiderable successes; in the transmutation of metals their failure is a matter of history.

But what are we of this so-called nineteenth century doing in our laboratories and our libraries? Too many of us are content to acquire simply what others have already observed and discovered, with an eye directed mainly to medals, certificates, diplomas, and other honours recognised as the fruits of "passing." Others are seeking to turn the determined facts of chemistry to useful purposes ; whilst a third class, sometimes not easily distinguished from the second, are daily educing novel organic compounds, or are racking their ingenuity to prepare artificially some product which Nature has hitherto furnished us through the instrumentality of plants and animals. The practical importance of such investigations, and their bearing on the industrial arts and on the purposes and needs of daily life, have been signally manifested during the last half-century.

Still a fourth class of inquirers working at the very confines of our knowledge find themselves, occasionally at least, face to face with a barrier which has hitherto proved impassable, but which must be overthruwn, surmounted, or turned, if chemical science is ever to develop into a definite, an organised, unity. This barrier is nothing less than the chemical elements commonly so called, the bodies as yet undecomposed int s anything simpler than themselves. There they extend before us, as stretched the wide Atlantic before the gaze of Columbus, mocking, taunting, and murmuring strange riddles which no man yet has been able to solve.

The first riddle, then, which we encounter in chemistry is, "What are the elements?" Of the attempts hitherto made to 
define or explain an element, none satisfy the demands of the human intellect. The text-books tell us that an element is " a body which has not been decomposed"; that it is "a something to which we can add, but from which we can take away nothing," or, "a body which increases in weight with every chemical change." Such definitions are -doubly unsatisfactory : they are provisional, and may cease to-morrow to be applicable in any given case. They take their stand, not on any attribute of the things to be defined, but on the limitations of human power; they are confessions of intellectual impotence.

Just as to Columbus long philosophic meditation led him to the fixed belief of the existence of a yet untrodden world beyond that waste of Atlantic waters, so to our most keen-eyed chemists, physicists, and philosophers a variety of phenomena suggest the conviction that the elements of ordinary assumption are not the ultimate boundary in this direction of the knowledge which man may hope to attain. Well do I remember, soon after I had obtained evidence of the distinct nature of thallium, that Faraday said to me--" To discover a new element is a very fine thing, but if you could decompose an element and tell us what it is made of that would be a discovery indeed worth making." And this was no new speculation of Faraday's, for in one of his early lecture he remarked-" At present we begin to feel impatient, and to wish for a new state of chemical elements. For a time the desire was to add to the metals, now we wish to diminish their number. ... To decompose the metals, then, to re-form them, to change them from one to another, and to realise the once absurd notion of transmutation, are the problems now given to the chemist for solution."

Mr. Herbert Spencer, in his hypothesis of the constitution of matter, says : "All material substances are divisible into so-called elementary substances composed of molecular particles of the same nature as themselves; but these molecular particles are complicated structures consisting of congregations of truly elementary atoms, identical in nature and differing only in position, arrangement, motion, \&c., and the molecules or chemical atoms are produced from the true or physical atoms by processes of evolution under conditions which chemistry has not yet been able to reproduce."

Mr. Norman Lockyer has shown, I think on good evidence, that in the heavenly bodies of the highest temperature a large number of our reputed elements are dissociated, or, as it would perhaps be better to say, have never been formed. Mr. Lockyer holds that "the temperature of the sun and the electric arc is high enough to dissociate some of the so-called chemical elements, and give us a glimpse of the spectra of their bases"; and he likewise says that "a terrestrial element is an exceedingly complicated thing that is broken up into simpler things at the temperature of the sun, and some of these things exist in some sun-spots, while other constituents exist in others."

The late Sir Benjamin Brodie, in a lecture on "Ideal Chemistry" delivered before the Chemical Society in 1867 , goes even further than this. He says :- "We may conceive that, in remote time or in remote space, there did exist formerly, or possibly do exist now, certain simpler forms of matter than we find on the surface of our globe-a, $\chi, \xi, \nu$, and so on.

We may consider that in remote ages the temperature of matter was much higher than it is now, and that these other things existed then in the state of perfect gases-separate existencesuncombined. . . . We may then conceive that the temperature began to fall, and these things to combine with one another and to enter into new forms of existence, appropriate to the circumstances in which they were placed. . . . We may further consider that, as the temperature went on falling, certain forms of matter became more permanent and more stable, to the exclusion of other forms. . . . We may conceive of this process of the lowering of the temperature going on, so that these substances, when once formed, could never be decomposed-in fact, that the resolution of these bodies into their component elements could never occur again. You would then have something of our present system of things.

"Now this is not purely an imagination, for when we look upon the surface of our globe we have actual evidence of similar changes in Nature. . . When we look at some of the facts which have been revealed to us by the extraordinary analyses which have been made of the matter of distant worlds and nebulæ, by means of the spectroscope, it does not seem incredible to me that there may even be evidence, some day, of the independent existence of such things as $\chi$ and $\nu$."

In his Burnett Lectures "On Light as a Means of Investiga- tion," Prof. Stokes, speaking of a line in the spectrum of the nebulæ, says :- " It may possibly indicate some form of matter more elementary than any we know on earth. There seems no a priori improbability in such a supposition so great as to lead us at once to reject it. Chemists have long speculated on the socalled elements, or many of them, being merely very stable compounds of elements of a higher order, or even perhaps of a single kind of matter."

In I868 Graham wrote of Sir W. Thomson's vortex-ring theory as enlivening "matter into an individual existence and constituting it a distinct substance or element."

From these passages, which might easily be multiplied, it plainly appears that the notion-not necessarily of the decomposability, but at any rate of the complexity, of our supposed elements-is, so to speak, in the air of science, waiting to take a further and more definite development. It is important to keep before men's minds the idea of the genesis of the elements ; this gives some form to our conceptions, and accustoms the mind to look for some physical production of atoms. It is still more important, too, to keep in view the great probability that there exist in Nature laboratories where atoms are formed, and Iaboratories where atioms cease to be. We are on the track and are not daunted, and fain would we enter the mysterious region which ignorance tickets "Unknown." It is for us to strive to unravel the secret composition even of the so-called elementsto undauntedly persevere - and "still bear up right onward."

If we adopt the easy-going assumption that the elements, whether self-existent or created, are absolutely and primordially distinct; that they existed as we now find them prior to the origin of stars and their attendant planets, constituting, in fact, the primal "fire-mist," we are little, if any, the wiser. We look at their number and at their distinctive properties, and we ask, Are all these points accidental or determinate? In other words, might there as well have been only 7, or 700 , or 7000 absolutely distinct elements as the 70 (in round numbers) which we now commonly recognise? The number of the elements does not, indeed, commend itself to our reason from any $a$ priori or extraneous considerations. Might their properties have conceivably differed from those which we actually observe? Are they formed by a "fortuitous concatenation," or do they constitute together a definite whole, in which each has its proper pert to play, and from which none could be extruded without leaving a recognisable deficiency?

If their peculiarities were accidental, it would scarcely be possible for the elements to display those mutual relations which we find brought into such prominent light and order in the periodic classification of Newlands, Mendeléeff, and Meyer. Has not the relation between the atomic weights of the three halogens, chlorine, bromine, and iodine, and their serially varying properties, physical and chemical, been worn nearly threadbare? And the same with the calcium and the sulphur groups? Surely the probability of such relations existing among some seventy bodies which had come into fortuitous existence would prove to be vanishingly small!

We ask whether these elements may not have been evolved from some few antecedent forms of matter-or possibly from only one such-just as it is now held that all the innumerable variations of plants and animals have been developed from fewer and earlier forms of organic life? As Dr. Gladstone well puts it, they "have been built up from one another, according to some general plan." This building up, or evolution, is above all things not fortuitous : the variation and development which we recognise in the universe run along certain fixed lines which have been preconceived and foreordained. To the careless and hasty eye, design and evolution seem antagonistic; the more careful inquirer sees that evolution, steadily proceeding along an ascending scale of excel!ence, is the strongest argument in favour of a preconceived plan.

The array of the elements cannot fail to remind us of the general aspect of the organic world. In both cases we see certain groups well filled up, even crowded with forms having among themselves but little specific difference. On the otber hand, in both, other forms stand widely isolated. Both display species that are common and species that are rare; both have groups widely distributed $-i t$ might be said cosmopolitan, and other groups of very restricted occurrence. Among animals I may mention as instances the Monotremata of Australia and New Guinea, and among the elements the metals of the so-called rare earths. 
Now as these facts in the distribution of organic forms are generally considered by biological experts to rank a nong the weightiest evidences in favour of the origin of species by a process of evolution, it seems natural, in this case as in the other, to view existing elements not as primordial but as the gradual outcome of a process of development, possibly even of a "struggle for existence." Bodies not in harmony with the present general conditions have disappeared or perhaps have never existed. Others - the asteroids among the elementshave come into being and have survived, but only on a limited scale; whilst a third class are abundant because surrounding conditions have been favourable to their formation and preservation.

The analogy here suggested between elements and organ isms is, indeed, not the closest, and must not be pushed too far. From the nature of the case there cannot occur in the elements a difference corresponding to the difference between living and fossil organic forms. The "great stone book" can tell us nothing of extinct elements. Nor would I for a moment suggest that any one of our present elements, however rare, is like a rare animal or plant in process of extinction; that any new element is in the course of formation, or that the properties of existing elements are gradually undergoing modification. All such changes must have been confined to that period so remote as not to be grasped by the imagination, when our earth, or rather the matter of which it consists, was in a state very different from its present condition. The epoch of elemental development is decidedly over, and I may observe that in the opinion of not a few biologists the epoch of organic development is verging upon its close.

Making, however, every allowance for these distinctions, if evolution be a cosmic law, manifest in heavenly bodies, in organic individuals, and in organic species, we shall in all probability recognise it, though under especial aspects, in those elements of which stars and organisms are in the last resort composed.

Is there then, in the first place, any direct evidence of the transmutation of any supposed "element" of our existing list into another, or of its resolution into anything simpler?

To this question I am obliged to reply in the negative.

I doubt whether any chemist here present conld suggest a process which would hold out a reasonable prospect of dissociating any of our accepted simple bodiez. The highest temperatures and the most powerful electric currents at our disposal have been tried, and tried in vain. At one time there seemed a possibility at least that the interesting researches of Prof. Victor Meyer might show the two higher nembers of the halogen group, bromine and iodine, as entering upon the path of dissociation. These hopes have not been fulfilled. It may be said, in the general opinion of the most eminent and judicious chemists, that none of the phenomena thus elicited prove that even an approach has been made to the object in view.

Even if we leave our artificial laboratories and seek an escape from the difficulty by observing the processes of the great laboratories of Nature, we feel no sufficiently firm ground.

We find ourselves thus driven to indirect evidence-to that which we may glean from the mutual relations of the elementary bodies. Such evidence of great value is by no means lacking, and to this I now beg to direct attention. First, we may consider the conclusion arrived at by Herschel, and pursued by Clerk-Maxwell, that atoms bear the impress of manufactured articles. Let us look a little more closely at this view. A manufactured article may well be supposed to involve a manufacturer. But it does something more : it implies certainly a raw material, and probably, though not certainly, the existence of by-products, residues, paraleipomena. What or where is here the raw material? Can we detect any form of matter which bears to the chemical elements a relation like that of a raw material to the finished product, like that, say, of coal-tar to alizarin? Or can we recognise any elementary bodies which seem like waste or refuse? Or are all the elements, according to the common view, co-equals? To these questions no direct answer is as yet forthcoming.

And this leads us up to an hypothesis which, if capable of ful demonstration, would show us that the accepted elements are not co-equal, but have been formed by a process of expansion or evolution. I refer to the well-known hypothesis of Prout, which regarls the atomic weights of the elements as multiples, by a series of whole numbers, of unity $=$ the atomic weight of hydrogen. Every one is aware that the recent more accurate determinations of the atomic weights of different elements do not by any means bring them into close harmony with the value: which Prout's law would require. Still, in no small number of cases the actual atomic weights approach so closely to those which the hypothesis demands, that we can scarcely regard the coincidence as accidental. Accordingly, not a few chemists of admitted eminence consider that we have here an expression of the truth, masked by some residual or collateral phenomena which we have not yet succeeded in eliminating.

The original calculations on which the most accurate numbers for the atomic weights are founded, have recently been re calculated by Mr. F. W. Clarke. In his concluding remarks, speaking of Prout's law, Mr. Clarke says that "none of the seeming exceptions are inexplicable. In short, admitting halfmultiples as legitimate, it is more probable that the few apparent exceptions are due to undetected constant errors than that the great number of close agreements should be merely accidental. I began this re-calculation of the atomic weights with a strong prejudice against Prout's hypothesis, but the facts as they came before me have forced me to give it a very respectful consideration."

But if the evidence in favour of Prout's hypothesis in its original guise is deemed insufficient, may not Mr. Clarke's suggestion of half-multiples place it upon an entirely new basis? Suppose that the unit of the scale, the body whose atomic weight if multiplied by a series of whole numbers gives the atoujic weights of the remaining elements, is not hydrogen, but some element of still lower atomic weight? We are here at once reminded of helium-an element purely hypothetical as far as our earth is concerned, but supposed by many authorities, on the faith of spectroscopic observations, to exist in the sun and in other stellar bodies. Most solar eruptions present merely the characteristic lines of hydrogen, $\mathrm{C}, \mathrm{F}$, and $\mathrm{H}$, and along with them one particular line which at first was classed in the sodium group, but which is a little more refrangible, and is designated by the symbol $\mathrm{D}_{3}$. According to $\mathrm{Mr}$. Norman Lockyer and the late Father Secchi, this ray undergoes modifications not comparable to those affecting other rays of the chromosphere. In the corresponding region of the spectrum no dark ray has been observed. That the accompanying lines, $\mathrm{C}, \mathrm{F}$, and $\mathrm{H}$, pertain to hydrogen is evident ; and as $D_{3}$ has never been obtained in any other spectrum it is supposed to belong to a body foreign to our earth, though existing in abundance in the chromosphere of the sun. To this hypothetical body the name helium is assigned.

In an able memoir on this subject read before the Academy of Brussels, the Abbé E. Spée shows that, if helium exists, it enjoys two very remarkable properties. Its spectrum consists of a single ray, and its vapour possesses no absorbent power. The simple single ray, though I believe unexampled, is by no means an impossible phenomenon, and indicates a remarkable simplicity of molecular constitution. The non-absorbent property of its vapour seems to be a serious objection to a general physical law. Prof. Tyndall has demonstrated that the absorptive power increases with the complexity of molecular structure, and hence he draws the conclusion that the simpler the molecule the feebler the absorption. This conclusion the Abbé Spée regards as perfectly legitimate; but it neither explains nor even necessitate: the absence of all absorptive power.

Granting that helium exists, all analogy points to its atomic weight being below that of hydrogen. Here, then, we may have the very element with atomic weight half that of hydrogen, required by Mr. Clarke as the basis of Prout's law.

But a more important piece of evidence for the compound nature of the chemical elements has yet to be considered. Many chemists must have been struck with certain peculiarities in the occurrence of the elements in the earth's crust; it is a stale remark that we do not find them evenly distributed throughout the globe. Nor are they associated in accordance with their specific gravities; the lighter elements placed on or near the surface, and the heavier ones following serially deeper and deeper. Neither can we trace any distinct relation between local climate and mineral distribution. And by no means can we say that elements are always or chiefly associated in Nature in the order of their so-called chemical affinities; those which have a strong tendency to form with each other definite chenical combinations being found together, whilst those which have little or no such tendency exist apart. We certainly find calcium as 
carbonate and sulphate, sodium as chloride, silver and lead as sulphides; but why do we find certain groups of elements with little affinity for each other yet existing in juxtaposition or commixture? The members of some of these groups are far from plentiful, not generally or widely diffused, and certainly they are not easy to separate.

As instances of such grouping we may mention :-

(I) Nickel and cobalt, of which it may be said that had their compounds been colourless, they would have been long regarded as identical, and possibly even yet would not have been separated.

(2) The two groups of platinum metals.

(3) The so-called "rare earths," occurring in gadolinite, samarskite, \&c., and evidently becoming more numerous the more closely they are examined.

Certain questions here suggest themselves:--Is the series of these elements like a staircase or like an inclined plane? Will they, the more closely they are scrutinised, be found to fade away the more gradually the one into the other? Further, will a mixture hitherto held to be simple, like (e.g.) didymium, be capable of being split up in one direction only, or in several? I have been led to ask this last question because I have separated from didymium bodies which seem to agree neither with the praseodymium and neodymium of Dr. Auer von Welsbach, nor with the components detected by $M$. de Boisbaudran and M. Demarçay.

Why, then, are these respective elements so closely associated? What agency has brought them together?

An eminent physicist evades the difficulty by suggesting that their joint occurrence is simply an instance of the working of the familiar principle, "Birds of a feath $>r$ flock together." In their chemical and physical attributes these rare earths are so closely similar, that they may be regarded as substantially identical in all the circumstances of solution and precipitation to which they may have been exposed during geological ages.

But do we, in point of fact, recognise any such agency at work in Nature? Is there any power which regularly and systematically sorts out the different kin Is of matter from promiscuous heaps, conveying like to like and separating unlike from unlike? I must confess that I fail to trace any such distributive agency, nor, indeed, do I feel able to form any distinct conception of its nature.

I must here remark that coral worms in some cases do effect a separation of certain kinds of matter. Thus a Gorgonia of the species of Melithar, and Mussa sinuosa, undoubtedly eliminate from sea-water not merely lime, but even yttria ; and other recent corals, Pocillopora damicornis, and a Symphyliza close to the yttria-secreting Mussa, separate samaria from sea-water. Sea-weeds and aquatic mollusks contain a larger proportion of iodide and bromine than the waters which they inhabit, and may thus be said to separate out these elements from the chlorine with which they are mingled.

But if we examine these cases of elimination we see that they are linited in their scope. They extend only to substances existing in solution of which there is a fresh supply always at hand, and which are capable of entering into the animal or vegetable economy. Again, the elimination of iodine and bromine, effected as just described, is of a very imperfect character, and, when such water-plants and animals die and decay, their constituents will be again distributed in the water.

We cann it well consider that nickel and cobalt have been deposited in admixture by organic agency, nor yet the groups iridium, osmium, and platinum-ruthenium, rhodium, and palladium.

Since the earthy metals to which I have referred-such as yttrium, samarium, holmium, erbium, thulium, ytterbium, \&c.are very rare, the probability of their ever having been brought together in some few uncommon minerals discovered only in a few localities must be regarded as trifling indeed, if we suppose that these metals had at any time been widely diffused in a state of great dilution with other matter. The features which we have just recognised in these earths seem to point to their formation severally from some common material placed in conditions in each case nearly identical. The case is strengthened by a consicleation of the other groups of elements, also similar in prop-ries, having little affinity for each other and occurring in admixture; either all or at least some of the elements concerned being moreover decidedly rare. Thus we have nickel and cobalt not plentiful or widely distributed; cobalt, perhaps, never found absolutely free from nickel, and vice virsâ. We have alio the two platinum groups, where very s.milar features prevail.

A weighty argument in favour of the compound nature of the elements is that drawn from a consideration of the compound radicals, or, as they might be called, pseudo-elements. Their similarity with the accepted elements is perfectly familiar to all chemists. If, for example, we suppose that in some age or in some country men of science were cognisant of the existence and of the behaviour of cyanogen, but had not succeeded in resolving it into its constituents, nothing, surely, would prevent their viewing it as an element, and assigning it a place with the halogens. It may fairly be held that if a body which we know to be compound can be found playing the part of an element, this fact lends a certain plausibility to the supposition that the elements also are not absolutely simple. This line of thought, or at least one closely approximating to it, was worked out by Dr. Carnelley in a paper read before this Association at its last meeting. From a comparison of the physical properties of inorganic with those of organic compoands, Dr. Carnelley concludes that "the elements, as a whole, are analogous to the hydrocarbon radicals." This conclusion, if true, he adds, should lead to the fut ther inference that the so-called elements are not truly elementary, being made up of at least two absolute elements, named provitionally $\mathrm{A}$ and $\mathrm{B}$. Hence, he argues, it should be posible to build up a series of coinpounds of these two primary ele nents which would correspond to what we now call elements. Such an arrangement, to be admissible, would have to fulfil certain conditions:- The secondary elements thus generated from $\mathrm{A}$ and $\mathrm{B}$ must exhibit the phenomena of periodicity, and the series would have to form octaves: the entire system is bound to display some feature corresponding to the "odd and even series" of Mendeléeff's classification; the atomic weights must increase across the system from the first to the seventh group - that is, from the positive to the negative end of each series; the atomicity would have to increase from the first to the middle group, and then either increase or decrease to the seventh group; some feature should appear corresponding to the eighth group; and, lastly, the atomic weights in such a system ought to agree with the atomic weights as experimentally determined.

This last condition Dr. Carnelley rightly regards as the most crucial, and he finds his arrangement gives atomic weights which in a majority of instances coincide approximately with the actual atomic weights. Thus out of a total of sixty-one elements whose atomic weights have been determined with at least approximate accuracy, and whose places in the periodic system is not disputed, twenty-seven agree almost exactly with the actual numbers, whilst nineteen others are not more than one unit astray.

For a detailed consideration of the conclusions which follow from Dr. Carnelley's views I must refer to his pap $\approx$ r as read at our last meeting. Two points bear more especially upon the subject now under consideration-that is, if this speculation on the genesis of the elements is well-founded. First, the existence of elements of identical atomic weights, isomeric with each other, would be possible ; as such, Dr. Carnelley mentions respectively nickel and cobalt (now found to have slightly different atomic weights), rhodium and ruthenium, osmium and iridium, and the metals of some of the rare earths. Secondly, in Dr. Carnelley's scheme all the chemical elements save hydroren are supposed to be composed of two simpler elements, $\mathrm{A}=\mathrm{I} 2$ and $\mathrm{B}=-2$. Of these he regards $\mathrm{A}$ as a tetrad identical with carbon, and $B$ as a monad of negative weight--perhaps the ethereal fluid of space.

Dr. Carnelley's three pri nary elements therefore are carbon, hydrogen, and the ether.

Starting from the supposition that pristine matter was once in an intensely heated condition, and that it has reached its present state by a process of free cooling, Dr. E. J. Mills suggests that the elements, as we now have them, are the result of successive polymerisations. Dr. Mills reminds us that chemical substances in the process of cooling naturally increase in density, and, if such increase be measured as a function of time or of temperature, we sometimes observe that there are critical points corre sponding to the formation of new and well-defined substances. In this manner ordinary phosphorus is converted into the red variety, $I$ is transformed into $\mathrm{I}_{2}, \mathrm{~S}_{2}$ becomes $\mathrm{S}_{6}$, and $\mathrm{NO}_{2} \mathrm{~N}_{2} \mathrm{O}_{4}$. Among organic bodies styrol, in like manner, according to Dr. 
Mills, is converted into metastyrol, aldehyd into paraldehyd, the cyanates into cyanurates, and turpentine into metaterebenthene. At the critical points above referred to heat is liberated in especial abundance, and the bodies thus formed are known as polymers. If we could gradually cool down substances through a vast range of temperature, we should then probably discover a much greater number of such critical points, or points of multiple proportion, than we have been able to discover experimentally.

The heat given out in the act of polymerisation naturally reverses to some extent the polymerisation itself, and so causes a partial return to the previous condition of things. This forward and backward movement, several times repeated, constitutes "periodicity." Dr. Mills regards variable stars as instances, now in evidence, of the genesis of elementary bodies.

From a study of the classification of the elements, Dr. Mills is of opinion that the only known polymers of the primitive matter are arsenic, antimony, and perhaps erbium and osmium; whilst zirconium, ruthenium, samarium, and platinum approximate to the positions of other polymers. Hence, from this genetic view, these elements may be described as products of successive polymerisations.

I must now call attention to a method of illustrating the periodic law, proposed by my friend Prof. Emerson Reynolds, of the University of Dublin, which will here assist us. Prof. Reynolds points out that in each period the general properties of the elements vary from one to another with approximate regularity until we reach the seventh member, which is in more or less striking contrast with the first element of the same period, as well as with the first of the next. Thus chlorine, the seventl member of Mendeléeff's third period, contrasts sharply both with solium, the first member of the same series, and with potassium, the first member of the next series, whilst, on the other hand, sodium and potassium are closely analogous. The six elements whose atomic weights intervene between sodium and potassium vary in properties, step by step, until chlorine, the contrast to sodium, is reached. But from chlorine to potassium, the analogue of sodium, there is a change in properties per saltum. Further, such alternations of gradual and abrupt transitions are observed as the atomic weights increase. If we thus recognise a contrast in properties-more or less decided-between the first and the last members of each series, we can scarcely help admitting the existence of a point of mean variation within each system. In general, the fourth element of each series possesses the propertie: we might expect a transitionelement to exhibit. It we examine a particular period-for instance, that one whose meso-element is silicon, we note:--First, that the three elements of lower atomic weight than silicon, viz. s indium, magnesium, and aluminium, are distinctly electro-positive in character, while those of higher atomic weight, viz. phosphorus, sulphur, and chlorine, are as distinctly electro-neyrative. Throughout the best-known periods this remarkable subdivision is observable, although, as might be anticipated, the differences become less strongly marked as the atomic weights increase. Secondly, that the members above and below the meso-element fall into pairs of elements, which, while exhibiting certain analogies, are generally in more or less direct chemical contrast. Thus, in the silicon period we have-

$$
\begin{array}{lll} 
& \mathrm{Si} \text { iv } & \\
+\mathrm{Al}^{\prime \prime \prime} & & \mathrm{P}^{\prime \prime \prime}- \\
+\mathrm{Mg}^{\prime \prime} & & \mathrm{S}^{\prime \prime}- \\
+\mathrm{Na}^{\prime} & & \mathrm{Cl}^{\prime}-
\end{array}
$$

This divison also happens, in many cases, to coincide with some characteristic valence of the contrasted elements. It is noteworthy, however, that the members on the electro-negative side exhibit the most marked tendency to vibration in atom-fixing power, so that valence alone is an untrustworthy guide to the probable position of an element in a period.

Thus for the purpose of graphic trans!ation Prof. Reynolds considers that the fourth member of a period-silicon, for example - may be placed at the apex of a symmetr:cal curve, which shall represent, for that particular period, the direction in which the properties of the series of elements vary with rising atomic weights.

In the drawing before you (Fig. I) I have modified Prof. Reynolds's diagram in one or two points. I have turned it the reverse way, as it is more convenient to start from the top and proceed downwards. I have represented the pendulous swing as gradually declining in amplitude, according to a mathe- matical law, and I have introduced another half swing of the pendulum between cerium and lead, which not only renders the os cillations more symmetrical, but brings gold, mercury, thal lium, lead, and bismuth on the side where they are in complete harmony with members of foregoing groups, instead of being out of harmony with them. This modification has another advantage, inasmuch as it leaves many gaps to be hereafter filled in with new elements just when the development of research is beginning to demand room for such expansion.

I do not, however, wish to infer that the gaps in Mendeléeff's table, and in this graphic representation of it, necessarily mean that there are elements actually existing to fill up the gaps; these gaps may only mean that at the birth of the elements there was an easy potentiality of the formation of an element which would fit into the place.

Following the curve from hydrogen downwards we find that the elements forming Mencleléeff's eighth group are to be found near three of the ten nodal points. These bodlies are "interperiodic," both because their atomic weights exclude them from the small periods into which the other elements fall, and because their chemical relations with certain members of the adjacent periods show that they are probably interperiodic in the sense of being transitional.

This eighth group is divided into the three triplets-iron, nickel, and cobalt; rhodium, ruthenium, and palladium; iridium, osmium, and platinum. The members of each triplet have often been regarded as modifications of one single form of matter.

Notice how accurately the series of like bodie: fits into this scheme. Beginning at the top, run the eye down analogous positions in each oscillation, taking either the electro-positive or electro-negative swings :-

$$
\begin{array}{lllllllllll}
\mathrm{N} & \mathrm{Be} & \mathrm{Li} & \mathrm{Na} & \mathrm{Mg} & \mathrm{Al} & \mathrm{Si} & \mathrm{P} & \mathrm{S} & \mathrm{Cl} & \mathrm{C} \\
\mathrm{V} & \mathrm{Ca} & \mathrm{K} & \mathrm{Cu} & \mathrm{Zn} & \mathrm{Ga} & \mathrm{Ge} & \mathrm{As} & \mathrm{Se} & \mathrm{Br} & \mathrm{Ti} \\
\mathrm{Nb} & \mathrm{Sr} & \mathrm{Rb} & \mathrm{Ag} & \mathrm{Cd} & \mathrm{In} & \mathrm{Sn} & \mathrm{Sb} & \mathrm{Te} & \mathrm{I} & \mathrm{Zr} \\
\overline{\mathrm{Ta}} & \mathrm{Ba} & \mathrm{Cs} & \overline{-} & \overline{\mathrm{Hg}} & \overline{\mathrm{Tl}} & \overline{\mathrm{Pb}} & \overline{\mathrm{Bi}} & - & - & -
\end{array}
$$

Notice, also, how orderly the metals discovered by spectrum analysis fit in their places-gallium, indium, and thallium.

The symmetry of nearly all this series proclaims at once that we are working in the right direction. We can also learn much from the anomalies here visible. Look at the places marked with a circle: didymium, samarium, holmium, erbium, ytterbium, and thulium. Didymium cannot follow in order after the triad nitrogen, vanadium, columbium ; nor erbium follow phosphorus, arsenic, antimony; nor thulium follow chlorine, bromine, iodine; nor ytterbium follow potassium, rubidium, cæsium. The inference to be drawn is that these bodies are out of place, owing to their atomic weights not having been correctly determined-an inference which is strengthened by the knowledge that the elementary character of some of these bodies is more than doubtful, whilst the chemical attributes of most of them are unknown.

The more I study the arrangement of this zigzag curve the more I am convinced that he who grasps the key will be permitted to unlock some of the deepest mysteries of creation. Let us imagine if it is possible to get a glimpse of a few of the secrets here hidden. Let us picture the very beginnings of time, before geological ages, before the earth was thrown off from the central nucleus of molten fluid, before even the sun himself had consulidatei from the original protyle. ${ }^{\mathrm{l}}$ Let us still imagine that at this primal stage all was in an ultra-gaseous state, at a temperature inconceivably hotter ${ }^{2}$ than anything now existing in the visible universe; so high, indeed, that the chem cal atoms could not yet have been formed, being still far above their dissociationpoint. In so far as protyle is capable of radiating or reflecting light, this vast sea of incandescent mist, to an astronomer in a distant star, might have appeared as a nebula, showing in the spectro cope a few isolated lines, forecasts of hydrogen, carbon, and nitrogen spectra.

${ }^{1}$ We require a word, analogous to protoplasm, to express the idea of the original primal matter existing before the evolution of the chemical ele. ments. The word I h ive ventured to use for this purpose is co:npounded of $\pi \rho_{0}$ (earlier than) and $i \lambda \eta$ (the stuff of which things are made). The word is scarcely a new coinage, for 600 years ago Roger Bacon wrote in his "De Arte Chymix":- "The elements are made out of $i \lambda \eta$, and every element is converted into the nature of another element."

$2 \mathrm{I}$ am constrained to use words expressive of high temperature : but I am constrained to use words expressive of high temperature; but I
confess I am unable clearly to associate with protyle the idea of hot or cold. Temperature, radiation, and free cooling seem to require the periodic Temperature, radiation, and free cooling seem to require the periodic
motions that take place in the chemical atoms; and the introduction of motions that take place in the chemical atoms; and the introduction of
centres of periodic motion into protyle would constitute its being so far centres of periodic motion
changed into chemical atoms. 
But in course of time some process akin to cooling, probably internal, reduces the temperature of the cosmic protyle to a point at which the first step in granulation takes place ; matter as we know it comes into existence, and atoms are formed. As soon as an atom is formed out of protyle it is a store of energy, potential (from its tendency to coalesce with other atoms by gravitation or chemically) and kinetic (from its internal motions). To obtain this energy, the neighbouring protyle must be refrigerated by it, ${ }^{1}$ and ther by the subsequent formation of other atoms will be accelerated. But with atomic matter the various forms of energy which require matter to render them evident begin to act; and, amongst others, that form of energy which has for one of its factors what we now call atonic weight. Let us assume that the elementary protyle contains within itself the potentiality of every possible combining proportion or atomic weight. Let it be granted that the whole of our known elements were not at this epoch simultaneously created. The easiest formed element, the one most nearly allied to the protyle

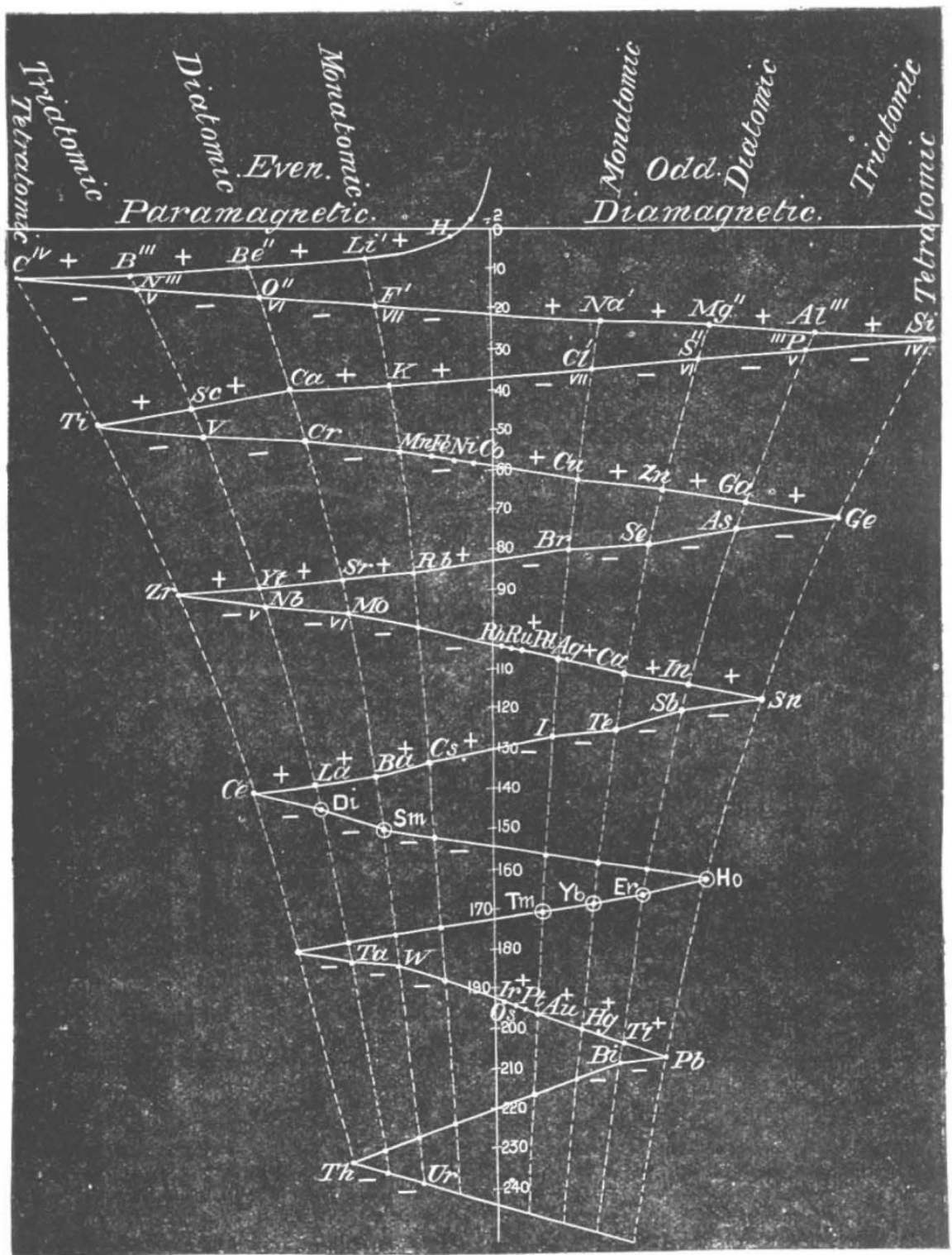

FIG. I.

in simplicity, is first born. Hydrogen - or shall we say helium? - of all the known elements the one of simplest structure and lowest atomic weight, is the first to come into being. For some tine hydrogen would be the only form of matter (as we now know it) in existence, and between hydrogen and the next formed element there would be a considerable gap in time, during the latter part of which the element next in order of simplicity would be slowly approashing its birth-point : pending

'I am indebted to my friend, G. John stone Stoney, F.R.S., for the idea here put forward, as well as for other valuable suggestions and criticisms on sone of the theoretical q restions here treated of this period we may suppose that the evolutionary process which soon was to determine the birth of a new element, would also determine its atomic weight, its affinities, and its chemical position.

In the original genesis, the longer the time occupied in that portion of the cooling down during which the hardening of the protyle into atoms took place the more sharply defined would be the resulting elements; and, on the other hand, with more irregularity in the original cooling we should have a nearer approach to the state of the elemental family such as we know it at present 
In this way it is conceivable that the succesion of events which gave us such groups as platinum, osmium, and iridium-palladium, ruthenium, and rhodium-iron, nickel, and cobalt, if the operation of genesis had been greatly more prolonged, would have resulted in the birth of only one element of these groups. It is also probable that, by a much more rapid rate of cooling, elements would originate even more closely related than are nickel and cobalt, and thus we should have formed the nearly allied elements of the cerium, yttrium, and similar groups; in fact, the minerals of the class of samarskite and gadolinite may be regarded as the cosmical lumber-room where the elements in a state of arrested development-the unconnected missing links of inorganic Darwinism-are finally aggregated.

I have said that the original protyle contained within itself the potentiality of all possible atomic weights. It may well be questioned whether there is an absolute uniformity in the mass of every ultimate atom of the same chemical eleinent. Probably our atomic weights merely represent a mean value around which the actual atomic weights of the atoms vary within certain narrow limits.

Each well-defined element represents a platform of stability connected by ladders of unstable bodies. In the first accreting together of the primitive stuff the smallest atoms would form, then these would join together to form larger groups, the gulf across from one stage to another would be gradually bridged over, and the stable element appropriate to that stage would absorb, as it were, the unstable rungs of the ladder which led up to it. I conceive, therefore, that when we say the atomic weight of, for instance, calcium is 40 , we really express the fact that, while the majority of calcium atoms have an actual atomic weight of 40 , there are not a few which are represented by 39 or 41 , a less number by 38 or 42 , and so on. We are here reminded of Newton's " old worn particles."

Is it not possible, or even feasible, that these heavier and lighter atoms may have been in some cases subsequently sorted out by a process resembling chemical fractionation? 'This sorting out may have taken place in part while atomic matter was condensing from the primal state of intense ignition, but also it may have been partly effected in geological ages by successive solutions and re-precipitations of the various earths.

This may seem an audacious speculation, but $I$ do not think it is beyond the power of chemistry to test its feasibility. An investigation on which I have been occupied for several years has yielded results which to me appear apposite to the question, and I therefore beg permission here to allude briefly to some of the

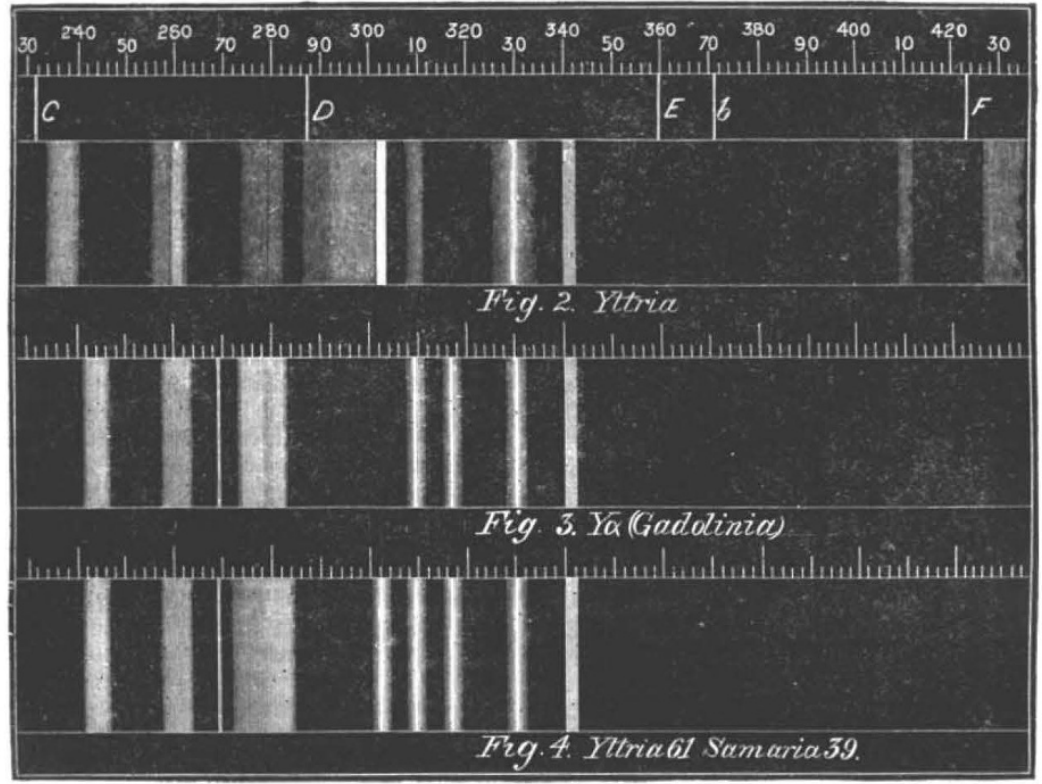

Figs. 2-4.

results, reserving details for a subsequent communication to the Section.

My work has been with the earths present in samarskite and gadolinite, separating them by systematic fractionation. Chemical fractionation, on which I hope to say more on another occasion, is very similar to the formation of a spectrum with a wide slit and a succession of shallow prisms. The centre portion remains unchanged for a long time, and the only approach to purity at first is at the two ends, while a considerable series of operations is needed to produce an appreciable change in the centre. The groups of didymium and yttrium earths are those which have chiefly occupied my attention. On comparing these rare earths we are at once struck with the close mutual similarity, verging almost into identity, of the members of the same group.

The phosphorescent spectra of these earths when their anhydrous sulphates are submitted to the induction discharge in vacuo are extremely complicated, and change in their details in a puzzling manner. For many years I have been persistently groping on in almost hopeless endeavour to get a clue to the meaning I felt convinced was locked up in these systems of bands and lines. It was impossible to divest myself of the conviction that I was looking at a series of autograph inscriptions from the molecular world, evidently of intense interest, but written in a strange and baffling tongue. All attempts to decipher the mysterious signs were, however, for a long time, fruitless. I required a Rosetta stone.

Down to a date comparatively recent nothing was me firmly fixed in my mind than the notion that yttria was the oxide of simple body, and that its phosphorescent spectrum gave a definite system of coloured bands, such as you see in the drawing before you (Fig. 2). Broadly speaking, there is a deep red band, a red band, a very luminous citron-coloured band, a pair of greenishblue tands, and a blue band. It is true these bands varied slightly in relative intensities and in sharpness with almost every sample of yttria I examined; but the general character of the spectrum remained unchanged, and I had got into the way of looking upon this spectrum as characteristic of yttria: all the bands being visible when the earth was present in quantity, whilst only the strongest band of all-the citron band-was visible when traces, such as millionths, were present. But that the whole system of bands spelled yttria and nothing but yttria I was firmly convinced.

During the later fractionations of the yttria earths, and the continued observations of their spectra, certain suspicions which had troubled me for some time assumed consistent form. The bands which hitherto I had thought belonged to yttria began to 
vary in intensity among themselves, and continued fractionation increased the differences first observed. Whilst I was in this state of doubt and uncertainty, and only beginning to see my way towards arranging into a consistent whole the facts daily coming to light, help came from an unexpected quarter. M. de Marignac, with whom I had been for some ti ne in correspondence, kindly sent me a small specimen of the earth which he had discovered and provisionally named $\mathrm{Y} \alpha$. In the radiant-matter tube this earth gave a bright spectrum like the one in the diagram before you (Fi. 3). The spectrum above it (Fig. 2) is that ascribed to yttria. I ook at the two. Omitting minor details, $\mathrm{Y} \alpha$ is yttria with the chief characteristic band--the citron band-left out, and with the double green band of samaria added to it. Now look at Fig. 4, which represents the spectrum of a mixture of $6 \mathbf{r}$ parts of yttria and 39 parts of samaria. It is identical almost to its minutest detail with the spectrum of $\mathrm{Y} \alpha$, with this not unimportant differe 3 ce--the citron band is as prominent as any other line. $\mathrm{Y} a$ consists, therefore, of samaria with the greenish blue of yttria and some of the other yttria bands added to it.

I may aptly call the $\mathrm{Y} \alpha$ spectrum my Rosetta stone. It threw a flood of light on all the obscurities and contradictions I had found so plentiful, and showed me that a much wider law than the one I had been working upon was the true law governing the oc surrence of these obscure phenomena. For what does the spectrum of $\mathrm{Y} \alpha$ show? It proves that what I had hitherto thought was one of the chief bands in the yttria spectrum-the citron band-could be entirely removed, whilst another characteristic group-the double green of yttria-could also be separated from the citron.

It would exceed legitimate limits were I to enter into details respecting the chemical and physical reasons which led me to these definite conclusions. To settle one single point more than 2000 fractionations have been performed.

The meaning of the strongly marked symbolic lines had first to be ascertained. For a long time I had to be content with roughly translating one group of coloured symbols as "yttrium" and another group as "samarium," disregarding the fainter lines, shadows, and wings frequently common to both. Constant practice in the decipherment has now given me fuller insight into what I may call the grammar of these hieroglyphic inscriptions. Every line and shadow of a line, each faint wing attached to a strong band, and every variation in intensity of the shadows and wings among themselves, now has a definite meaning which can be translated into the common symbolism of chemistry.

In a mineral containing the rarer earths, those most widely separated in chemical properties are most easily obtained in a state of comparative purity by simple chemical means. For instance, in separating didymium from lanthanum, or samarium from yttrium, a few simple chemical reactions and a little waste will give these bodies in a state of purity; but when it comes to splitting up yttrium into its components ordinary chemical separation is useless, and fractionation must be pushed to the utmost limit, many thousand operations and enormous waste of material being necessary to effect even a partial separation.

Returning therefore, after this explanatory digression, to the idea of heavy and light atoms, we see how well this hypothesis accords with the new facts here brought to light. From tvery chemical point of view the stable molecular group, yttrium, behaves as an element. Excessive and systematic fractionation has acted the part of a chemical "sorting Demon," distributing the atoms of ytrrium into several groups, with certainly different phosphorescent spectra, and presumably different atomic weights, though all these groups behave alike from the usual chemical point of view. Here, then, is one of the elements the spectrum of which does not emanate equally from all its atoms, but some atoms furnish some, other atoms others, of the lines and bands of the compound spectrum of the element. And as this is the case with one element, it is probably so in a greater or les; degree with all. Hence the atoms of this element differ probably in weight, certainly in the internal motions they undergo.

Another important inference which may be drawn from the facts is, that the atoms of which yttrium consists, though differing, do not differ continuously, but per saltum. We have evidence of this in the fact that the spectroscupic bands charac. teristic of each group are distinct from those of the other groups, and do not pass gradually into tbem. We must accordingly expect, in the present state of science, that this is probably the case with the other elements. And the atoms of a chemical element being known to differ in one respect may differ in other respects, and presumably do somewhat differ in mass.

Restricted by limited time and means, even a partial separation of these atomic groupings is possible to me only with enormous difficulty. Have we any evidence that Nature has effected such a separation? The following facts, I think, supply this evidence.

The earth yttria occurs in several minerals, all extremely rare. These minerals are of very diverse chemical composition, and occur in localities widely separated geographically. Does the pure yttria (pure in respect to every other known element) from these different sources behave differently to the radiant-matter test ? To the chemist hitherto the earth yttria has been the sa ne thing, and has possessed the same properties whatever its source; but armed with this new power of seeing into the atomic groupings which go to make up yttrium, we find evidence of differentiation between one yttrium and another.

Thus when the samarskite yttrium was formed, all the constituent atoms-deep red, red, orange, citron, greenish blue, and blue ${ }^{1}$ - condensed together in fair proportion, the deep red being. faintest. In gadolinite yttrium the citron and greenish blue constituents are plentiful, the red is very deficient, the orange is absent, and the others occur in moderate quantities. In the yttrium from xenotime the citron is most plentiful, the greenish blue occurs in smaller proportion, the red is all but absent, and the orange is quite absent. Yttrium from monazite contains the greenish blue and citron, with a fair proportion of the other constituents; the greenish blue is plentiful, and the red is good. Ytrium from fiuocerite is very similar to that from monazite, but the blue is weaker. Yttrium from hielmite is very rich in citron, has a fair quantity of blue and greenish blue, less of red, no orange, and only a very faint trace of deep red. Yttria from euxenite is almost identical with that from hielmite.

This is unlikely to be an isolated case. The principle is very probably of general application to all the elements. In some, possibly in all elements, the whole spectrum does not emanate from all its atoms, but different spectral rays may come from different atoms, and in the spectrum as we see it all these partial spectra are present together. This being interpreted means that there are definite differences in the internal motions which go on in the several groups of which the atoms of a chemical element consist. For example, we must now be prepared for some such events as that the seven series of bands in the absorption-spectrum of iodine may prove not all to emanate from every molecule, but that some of these molecules emit some of these series, others others, and in the jumble of all these kinds of molecules, to which is given the name "iodine vapour," the whole seven series are contributors.

To me it appears the theory I have here ventured to formulate, taken in conjunction with the diagram in Fig. 1 , may aid the scientific imagination to proceed a step or two further in the order of elemental evolution. In the undulating curve may be seen the action of two forces, one acting in the direction of the vertical line, and the other pulsating backwards and forwards like a pendulum. Assume the vertical line to represent temperature slowly sinking through an unknown number of degrees, from the dissociation point of the first-formed element down to the dissociation point of those last shown on the scale. But what form of energy is represented by the oscillating line? Swinging to and fro like a mighty pendulum to points equidistant from a neutral centre; the divergence from neutrality conferring atomicity of one, two, three, and four degrees as the distance from the centre is one, two, three, or four divisions; and the approach to, or retreat from, the neutral line deciding the electro-negative or electro-positive character of the element -all on the retreating half of the swing being positive and all on the approaching half negative-this oscillating force must be intimately connected with the imponderable matter, essence, or source of energy we call electricity.

Let us examine this a little more closely. Let us start at the moment when the first element came into existence. Before this time matter, as we know it, was not. It is equally impossible to conceive of matter without energy, as of energy without matter ; from one point of view the two are convertible terms. Before the birth of atoms all those forms of energy which become evident when matter acts upon matter, could not have existed-they were locked up in the protyle as latent potentialities

\footnotetext{
I For bevity I call them by thei- domi an: spectrum band.
} 
only. Coincident with the creation of atoms all those attributes and properties which form the means of discriminating one chemical element from another start into existence fully endowed with energy.

The pendulum begins its swing from the electro-positive side ; lithium, next to hydrogen in simplicity of atomic weight, is now formed; then glucinum, boron, and carbon. Definite quantities of electricity are bestowed on each element at the moment of birth, on these quantities its atomicity depends, ${ }^{1}$ and the types of monatomic, diatomic, triatomic, and tetratomic elements are fixed. The electro-negative part of the swing now commences; nitrogen appears, and notice how curiously position governs the mean dominant atomicity. Nitrogen occupies the position below boron, a triatomic element, therefore nitrogen is triatomic. But nitrogen also follows carbon, a tetratomic body, and occupies the fifth position counting from the place of origin ; how beautifully these opposing tendencies are harmonised by the endowment of nitrogen with at least a double atomicity, and making its atom capable of acting as tri- and pentatomic. With oxygen (di- and hexatomic) and fluorine (mon-and heptatomic) the same law holds, and one half-oscillation of the pendulum is completed. Again passing the neutral line the electro-positive elements, sodium (monatomic), magnesium (diatomic), aluminium (triatomic), and silicon (tetratomic) are successively formed, and the first complete oscillation of the pendulum is finished by the birth of the electro-negative elements phosphorus, sulphur, and chlorine; these three-like the corresponding elements formed on the opposite homeward swing - having each at least a double atomicity depending on position.

Let us pause at the end of the first complete vibration and examine the result. We have already formed the elements of water, ammonia, carbonic acid, the atmosphere, plant and animal life, phosphorus for the brain, salt for the sea, clay for the solid earth, two alkalies, an alkaline earth, an earth, together with their carbonates, borates, nitrates, fluorides, chlorides, sulphates, phosphates, and silicates, sufficient for a world and inhabitants not so very different from what we enjoy at the present day. True the human inhabitants would have to live in a state of more than Arcadian simplicity, and the absence of calcic phosphate would be awkward as far as bone is concerned. But what a happy world it would be! No silver or gold coinage, no iron for machinery, ro platinum for chemists, no copper wire for telegraphy, no zinc for batteries, no mercury for pumps, and, alas! no rare earths to be separated.

The pendulum does not, however, stop at the end of the first complete vibration; it crosses the neutral point, and now the forces at work are in the same position as they were at the beginning. Had everything been as it was at first the next element again would have been lithium, and the original cycle would have recurred, repeating for ever the same elements. But the conditions are not quite the same ; the form of energy represented by the vertical line has declined a little-the temperature has sunk-and not lithium, but the one next allied to it in the series comes into existence-potassium, which may be regarded as the lineal descendant of lithium, with the same hereditary tendencies, but with less molecular mobility and higher atomic weight.

Pass we rapidly along the to-and-fro curve, and in nearly every case the same law is seen to hold good. The last element of the first complete vibration is chlorine. In the corresponding place in the second vibration we do not have an exact repetition of chlorine, but the very similar body bromine ; and when for a third time the position recurs we see iodine. I need not multiply examples.

In this far-reaching evolutionary scheme it could not come to pass that the potential elements would all be equal to one another. Some would be unable to resist the slightest disturbance of the unstable equilibrium in which they took their rise; others would endure longer, but would ultimately break down as temperature and pressure varied. Many degrees of stability

1 "Nature presents us with a single definite quantity of electricity. .

For each chemical bond which is ruptured within an electrolyte a certain quantity of electricity traverses the electrolyte, which is the same in all cases."-G. Johnstone STONeY, "On the Physical Units of Nature," British Association Meeting, 1874, Section A. Phil. Mag., May 188r. "The same definite quantity of either positive or negative electricity moves always with each univalent ion, or with every unit of affinity of a multivalent ion."-HEL.MHOLTZ, Faraday Lecture, 188r.

"Every monad atom has asso ciated with it a certain definite quantity of electricity ; every dyad has twice this quantity associated with it; every triad three times as much, and so on."-O. Longe, "On Electrolysis," "British Association Report," 1885. would be here represented; not all the chemical elements are equally stable, and if we look with scrutinising eyes we shall still see our old friend the missing link, coarse enough to be detected by ordinary chemical processes, associated in the groups containing such elements as iron, nickel, and cobalt ; palladium, rutbenium, and rhodium; iridium, osmium, and platinum. Whilst in their more subtile form these missing links present themselves as representatives of the differences which I have detected and described between the atoms of the same chemical element.

Dr. Carnelley has pointed out that "those elements belonging to the even series of Mendeléeff's classification are always paramagnetic, whereas the elements belonging to the odd series are always diamagnetic." On this curve the even series to the left, as far as can be ascertained, are paramagnetic, and, with a few exceptions, all to the right are diamagnetic. The very powerful magnetic metals, iron, nickel, cobalt, and manganese, occur close together on the proper side. The interperiodic groups, of which palladium and platinum are examples, are said to be feebly magnetic, and, if so, they form the exceptions. Oxygen, which weight for weight is more magnetic than iron, comes near the beginning of the curve, while the powerfully diamagnetic metals, bismuth and thallium, are at the opposite end of the curve.

On the odd, or diamagnetic, half of the swing the energy appears to have considerable regularity, whilst it is very irregular on the opposite side of the curve. Thus, between the extreme odd elements, silicon (28), germanium (73), tin (II8), the missing element ( 163 ), and lead (208), there is a difference of exactly 45 units, conferring remarkable symmetry on one half of the curve. The differences on the even side are $36,42,51,39$, and 53 (giving the missing element between cerium and thorium an atomic weight of 180); these at first sight appear conformable to no law, but they become of great interest when it is seen that the mean difference of these figures is almost exactly the same as that on the other side of the curve-viz. $44^{\circ} 2$.

This uniformity of difference-actual on the one side and average on the other-brings out the important inference that, whilst on the odd side there has been little or no variation in the vertical force, minor irregularities have been the rule on the even side. That is to say, the fall of temperature has been very uniform on the odd side-where every element formed during this half of the vibration is the representative of a stronglymarked group-sodium, magnesium, aluminium, silicium, phosphorus, sulphur, and chlorine; whilst on the even side of the swing the temperature has sunk with considerable fluctuations, which have prevented the formation here of any well-marked groups of elements, with the exception of those of which lithium and glucinum are the types.

If we can thus trace irregularities in the fall of temperature, can we also detect any variation in the force represented by the pendulous movement? I have assumed that this represents chemical energy. In the early-formed elements we have those in which chemical energy is at its maximum intensity, while, as we descend, affinities for oxygen are getting less and the chemism is becoming more and more sluggish. Part may be due to the lower temperature of generation not permitling such molecular mobility in the elements, but there can be little doubt that the chemism-forming energy, like the fires of the cosmical furnace, is itself dying out. I have endeavoured to represent this gradual fading out by a diminution of amplitude, the curve being traced from a photingraphic record of the diminution of the arc of vibration of a body swinging in a resisting medium.

When we look on a curve of this kind there is a tendency to ask, What is there above and below that portion which is seen? At the lower end of our curve what is there to be noted ? We see a great hiatus between barium (137) and iridium (I92.5), which it seems likely will be filled up by the so-called rare elements. Judging from my own researches, it is probable that many of these earthy elements will be found included in one or more interperiodic groups, whilst the higher members of the calcium, the potassium, the chlorine, and the sulphur groups, together with the elements between silver and gold, cadmium and mercury, indium and thallium, antimony and bismuth, are still waiting to be discovered. We now come to an oasis in the desert of hlanks. Platinum, gold, mercury, thallium, lead, and bismuth, all familiar friends, form a close little group by themselves, and then after another desert space the list is closed with thorium (233) and uranium (240).

This oasis, and the blanks which precede and follow it, may 
be referred with much probability to the particular way in which our earth developed into a member of our solar system. If this be so it may be that on our earth only these blanks occur, and inot generally thruughout the universe.

II hat comes after uranium? I should consider that there is little prospect of the existence of an element much lower than this. Look at the vertical line of temperature slowly sinking from the upper to the lower part of the curve; the figures representing the scale of atomic weights may be also supposed to represent, inversely, the scale of a gigantic pyrometer dipping into the cauldron where suns and worlds are in process of formation. Our thermometer shows us that the heat has been sinking gradually, and, pari pussu, the elements formed have increased in density and atomic weight. This cannot go on for an indefinite extent. Below the uranium point the temperature may be so reduced that some of the earlier formed elements which have the strongest affinities are able to enter into combination among themselves, and the result of the next fall in temperature will then be-instead of elements lower in the scale than uranium - the combination of oxygen with hydrogen, and the formation of those known compounds the dissociation of which is not beyond the powers of our terrestrial sources of heat.

Let us now turn to the upper portion of the scheme. With hydrogen of atomic weight $=\mathrm{I}$, there is little room for other elements, save perhaps for hypothetical helium. But what if we get " through the looking-glass," and cross the zero-line in search of new principles--what shall we find the other side of zero? Dr. Carnelley asks for an element of negative atomic weight; here is ample room and verge enough for a shadow series of such unsubstantialities. Helmholtz says that electricity is probably as atomic as matter $:^{1}$ is electricity one of the negative elements, and the luminiferous ether another? Matter, as we now know it, does not here exist; the forms of energy which are apparent in the motions of matter are as yet only latent possibilities. A substance of negative weight is not inconceivable." ${ }^{2}$ But can we form a clear conception of a body which combines with other bodies in proportions expressible by negative quantities?

A genesis of the elements such as is here sketched out would not be confined to our little solar system, but would probably follow the same general sequence of events in every centre of energy now visible as a star.

Before the birth of atoms to gravitate towards one another, no pressure could be exercised ; but at the outskirts of the firemist sphere, within which all is protyle -at the shell on which the tremendous forces involved in the birth of a chemical element exert full sway--the fierce heat would be accompanied by gravitation sufficient to keep the newly-born elements from flying off into space. As temperature increases expansion and molecular motion increase, molecules tend to fly asunder, and their chemical affinities become deadened; but the enormous pressure of the gravitation of the mass of atomic matter outside what I may for brevity call the birth-shell would counteract this action of heat.

Beyond this birth-shell would be a space in which no chemical action could take place, owing to the temperature there being above what is called the dissociation point for compounds. In this space the lion and the lamb would lie down together; phosphorus and oxygen would mix without union; hydrogen and chlorine would show no tendency to closer bonds; and even fluorine, that energetic gas which chemists have only isolated within the last month or two, would float about free and uncombined.

Outside this space of free atomic matter would be another shell, in which the formed chemical elements would have cooled down to the combination-point, and the sequence of events so graphically described by Mr. Mattieu Williams in "The Fuel of the Sun "would now take place, culminating in the solid earth and the commencement of geological time.

And now I must draw to a close, having exhausted not indeed my subject, but the time I may reasonably occupy. We have glanced at the difficulty of defining an element; we have noticed

1 "If we accept the bypothesis that the elementary substances are com1 "If we accept the hypothesis that the elementary substances are com
posed of atoms, we cannot avoid concluding that electricity also, positive as posed of atoms, we cannot avoid concluding that electricity also, positive as
well as negative, is divided into definite elementary portions, which behave well as negative, is divided into definite elementary portions, wh
like atoms of electricity."-HELMHOLTZ, Faraday Lecture, 188I.

like atoms of electricity."- HELMHOLTZ, Faraday Lecture, 188I.
2 "I can easily conceive that there are plenty of bodies about us not subject to this intermutual action, and therefore not subject to the law of gravitation."-SIR GEORGE AIRY, "Faraday's Life and Letters," vol. ii p. 354 too the revolt of many leading physicists and chemists against the ordinary acceptation of the term element. We have weighed the improbability of their et ernal self-existence, or their origination by chance. As a remaining alternative we have suggested their origin by a process of evolution like that of the heavenly bodies according to Laplace, and the plants and animals of our globe according to Lamarck, Darwin, and Wallace. In the general array of the elements, as known to us, we have seen a striking approximation to that of the organic world. In lack of direct evidence of the decomposition of any element, we have sought and found indirect evidence. We have taken into consideration the light thrown on this subject by Prout's law, and by the researches of Mr. Lockyer in solar spectroscopy. We have reviewed the very important evidence drawn from the distribution and collocation of the elements in the crust of our earth. We have studied Dr. Carnelley's weighty argument in favour of the compound nature of the so-called elements from their analogy to the compound radicals. We have next glanced at the view of the genesis of the elements; and, lastly, we have reviewed a scheme of their origin suggested by Prof. Reynolds's method of illustrating the periodic classification.

Summing up all the above con:iderations we cannot, indeed, venture to assert positively that our so-called elements have been evolved from one primordial matter; but we may contend that the balance of evidence, I think, fairly weighs in favour of this speculation.

This, then, is the intricate question which I have striven to unfold before you, a question that I especially commend to the young generation of chemists, not only as the most interesting, but the most profoundly important, in the entire compass of our science.

I say deliberately and advisedly the most interesting. The doctrine of evolution, as you well know, has thrown a new light upon and given a new impetus to every department of biology, leading us, may we not hope, to anticipate a corresponding wakening light in the domain of chemistry?

I would ask investigators not necessarily either to accept or to reject the hypothesis of chemical evolution, but to treat it as a provisional hypothesis; to keep it in view in their researches, to inquire how far it lends itself to the interpretation of the phenomena observed, and to test experimentally every line of thought which points in this direction. Of the difficulties of this investigation none can be more fully aware than myself. I sincereiy hope that this my imperfect attempt may lead some minds to enter upon the study of this fundamental chemical question, and to examine closely and in detail what $\mathrm{I}$, as if amidst the clouds and mists of a far distance, have striven to point out.

\section{NOTES}

A Reuter's telegram dated Grenada, August 29, states that during the solar eclipse of that morning good photometric observations were made by Prof. Thorpe. The light during the middle of totality was less than from the full moon. We learn from later telegrams dated Grenada, August 3I, that the eclipse of the sun has been well observed by the British Astronomical Expedition, and that in the observations taken it was noticed that the corona extended nearly two diameters from the sun, and exhibited a feathery structure at the poles. Good photographs have been obtained of the coronal spectrum in the blue end. The spectrum was similar to that of the eclipse of $188_{3}$, observed on the Caroline Islands.

THE celebrations connected with the Chevreul centenary took place in Paris on Tuesday last. The first demonstration was that of the National Society of Agriculture, to which M. Chevreul was elected member forty-six years ago, and of which he is elected President every alternate year. A commemoration medal was struck by the same Society. At three o'clock M. Chevreul received the congratulations of the members of the Academy of Sciences. The principal ceremony of the day was the unveiling of the statue of M. Chevreul in the hall of the new Museum at the Jardin des Plantes. The walls of the room, which are of vast dimensions, were hung with red velvet, and 